\title{
HEALTH IN TRANSITION
}

Translating developmental origins of health and disease science to improve future health in Africa

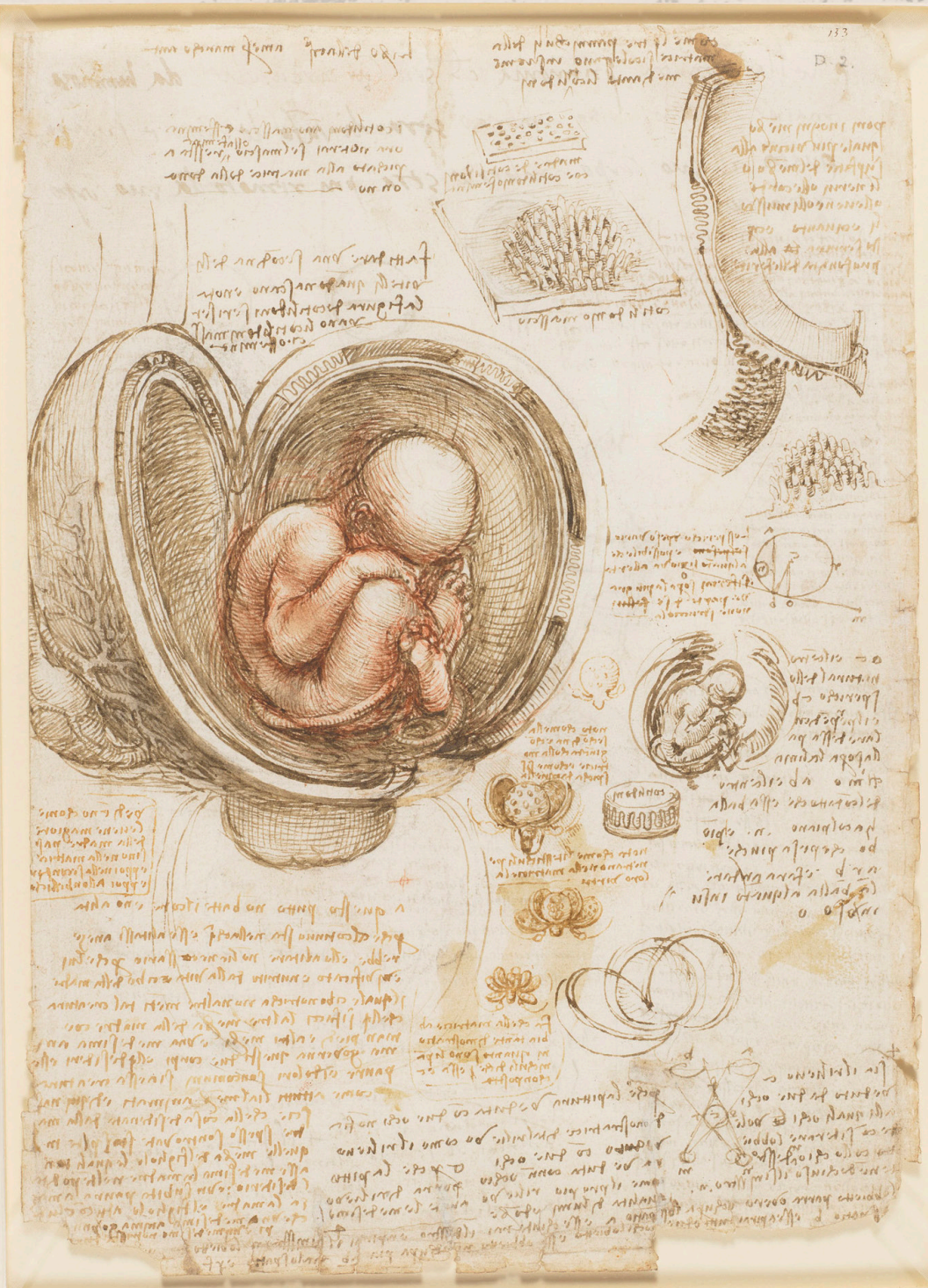

ANDREW J MACNAB, ABDALLAH DAAR \& CHRISTOFF PAUW 

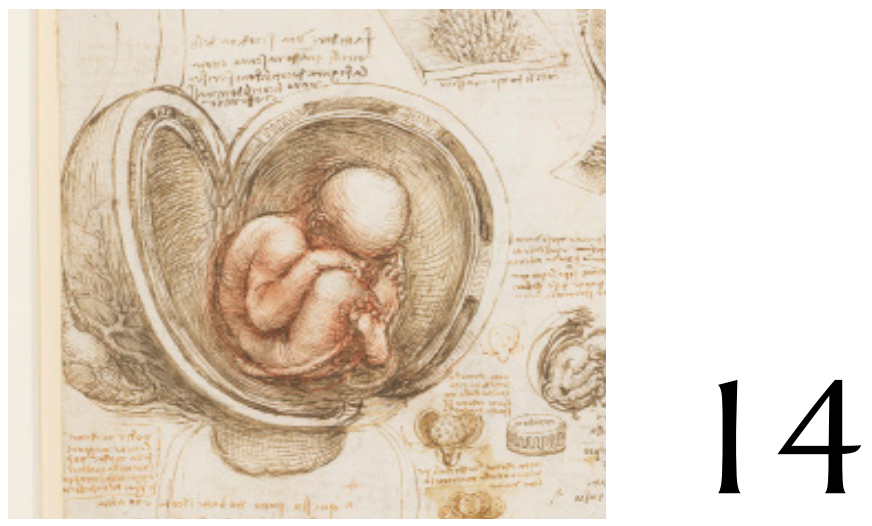

\section{SCHOOL-BASED INITIATIVES TO REDUCE MALARIA MORBIDITY AND PROMOTE ACADEMIC ACHIEVEMENT IN CHILDREN}

Andrew | Macnab

In sub-Saharan Africa, the challenge of addressing illnesses related to the developmental origins of health and disease $(\mathrm{DOHaD})$ is compounded by other determinants of health, most notably the impact of poverty and infectious disease. Research has identified social factors to be the root cause of inequities in health that involve both non-communicable and infectious diseases, hence the calls for remedial action to involve social and treatment strategies.

There is a recognised need for school programmes to educate the next generation about $\mathrm{DOHaD}$, so that young people gain a measure of 'health independence' through learned knowledge, acquired skills and positive behaviours with the potential to improve the future health of their offspring. However, this goal is at risk when other adverse social determinants of health exist, and especially where

1 Stellenbosch Institute for Advanced Study, Wallenberg Research Centre at Stellenbosch University, Stellenbosch, South Africa; Department of Pediatrics, The University of British Columbia, Vancouver, BC, Canada. 
infectious diseases are endemic, and morbidity from infection among school children is high. In sub-Saharan Africa, for example, malaria is the principal reason a child will be absent from school. How long a child is absent is a well-accepted measure of the severity of morbidity from malaria. Such absences can be of long duration, and associated residual cognitive compromise can compound the negative impact of malaria on a child's ability to learn.

For this reason, school-based strategies to advance knowledge about $\mathrm{DOHaD}$ in sub-Saharan Africa will benefit where school-based programmes addressing malaria are offered in parallel. A variety of educational approaches able to advance knowledge and provide practical skills related to $\mathrm{DOHaD}$ lend themselves to parallel programmes. For example, programmes can follow policies to advance the United Nations (UN)' 'Sustainable Development Goals', adopt global strategies to promote the education of girls and implement the World Health Organization (WHO)'s 'Health-Promoting School' model. Malaria morbidity exemplifies how health inequity can negatively impact a child's ability to benefit from education. However, simple and effective school-based approaches exist that can positively impact morbidity, provide access to diagnostic and treatment services, reduce absence due to illness and increase the capacity of large numbers of children to learn.

This chapter reviews global efforts to reduce the impact of malaria on children's health, improve their ability to attend school, enhance their potential for academic achievement and minimise their risk of cognitive impairment. It also describes a successful and inexpensive community participatory intervention model based on WHO-endorsed diagnostic and treatment principles, that also follows the 2017 Lancet Commission's current recommendations on the future of health in subSaharan Africa to use 'non-traditional outlets', 'people-centred approaches' and 'improved tools' to address health challenges. This model is suitable for use in schools worldwide where malaria is endemic and can be offered in parallel with school-based strategies to engage youth in the context of the $\mathrm{DOHaD}$ agenda.

\section{Introduction}

The gross inequalities in health that we see within and between countries present a challenge to the world. A burgeoning volume of research identifies social factors at the root of much of these inequalities in health. Social determinants are relevant to communicable and non-communicable disease alike. ${ }^{2}$

2 Marmot, M., Friel, S., Bell, R., Houweling, T.A. \& Taylor, S. 2008. Closing the gap in a generation: health equity through action on the social determinants of health. The Lancet, 372(9650):1661-1669. [https://doi.org/10.1016/S0140-6736(08)61690-6]. 
Globally, malaria kills more than one million people a year, and perhaps closer to three million when the role of malaria in deaths related to other disease is included. Much mortality in endemic areas is concentrated among children under the age of five years. The number of school-aged children (five to 14 years) who die from malaria is unknown, but in many low- and middle-income countries worldwide, malaria is cited to be the principal reason why a child will be absent from school.

The duration of malaria-related absence, frequency of absence due to repeated infection, residual malaise from sub-optimal treatment and temporary or permanent neurological complications of falciparum malaria are all known to compromise a child's potential to learn. School-age children however have attracted relatively little attention as a group in need of special measures to protect them against malaria. Significantly, it is also anticipated that in coming years there will be an increase in the incidence of both uncomplicated and severe malaria in schoolchildren in previously high endemic areas, because of the tendency for this age group to acquire immunity later in life.

The burden of disease from malaria is greatest among children in low resource settings. Poverty and malaria are inextricably linked. Poverty is concentrated in the tropical and sub-tropical zones where malaria thrives. Poverty per se may promote malaria transmission; malaria may cause poverty by impeding individual and societal economic growth - most likely, causality runs in both directions.

Schools promoting health, including those which use the WHO's HealthPromoting School model, provide opportunities within the formal curriculum to increase 'knowledge' and promote 'healthy practices,' hence the relevance of this model for engaging youth in the context of a range of socially relevant health issues, including the current epidemic of non-communicable diseases, like type 2 diabetes and heart disease. While many schools in Africa include education related to health, the ability of pupils to benefit is often negatively impacted by social determinants of health, which means that the effect of such programmes is limited.

Malaria, for example, robs a child of the ability to attend school, the capacity to be fully present in class when convalescent, and their long-term academic potential if they suffer permanent sequalae. A social factor in this regard is that most teachers send home children found to be sick at school, thereby devolving care decisions to parents. In many families, lack of knowledge about appropriate care for children with probable malaria, and limited access to care facilities in the community, commonly contribute to morbidity, as in many cases appropriate diagnosis and treatment do not occur, or at best are often delayed.

For these reasons, there are widespread calls for innovation and implementation of programmes to address malaria mortality and morbidity in school-age children. 


\section{Methods}

Searches were undertaken of the published literature on malaria in children using the following search terms, singly, or in combination - malaria, children, school, school children, school-based, teachers, teacher-based, rapid diagnostic testing, artemisinin combination therapy, chemoprevention, Africa, sub-Saharan Africa. Search results were supplemented by papers identified from the reference lists published in these papers and material familiar to the author. The review was limited to the English language and focused predominantly on Africa and research published in the last 20 years, except where prior work had historical relevance.

\section{Background}

School-age children have attracted relatively little attention as a group in need of special measures to protect them against malaria. ${ }^{3}$

New and better diagnostic approaches are required to address malaria in children because of the current levels of morbidity and mortality. ${ }^{4}$ Schools present an obvious and logical opportunity to improve the access of school children to timely diagnosis and treatment. ${ }^{5}$ However, currently, national malaria control interventions do not specifically target school-age children despite increasing evidence that this age group bears the highest burden of infection. ${ }^{6}$ Awareness of the impact of malaria among school-age children has stimulated investigation into

3 Nankabirwa, J., Brooker, S.J., Clarke, SE., Fernando, D., Gitonga, C.W., Schellenberg, D. \& Greenwood, B. 2014a. Malaria in school-age children in Africa: an increasingly important challenge. Tropical Medicine \& International Health, 19(11):1294-1309. [https://doi.org/10.1111\%2Ftmi.12374].

4 Bell, D., Fleurent, A.E., Hegg, M.C., Boomgard, J.D. \& McConnico, C.C. 2016. Development of new malaria diagnostics: matching performance and need. Malaria Journal, 15(406). [https://doi.org/10.1186/s12936-016-1454-8].

5 Temperley, M., Mueller, D.H., Njagi, J.K., Akhwale, W., Clarke, S.E., Jukes, M.C.H., Estambale, B. \& Brooker, S. 2008. Costs and cost-effectiveness of delivering intermittent preventive treatment through schools in western Kenya. Malaria Journal, 7(196).

[https://doi.org/10.1186/1475-2875-7-196]; Macnab, A.J., Mukisa, R., Mutabazi, S. \& Steed, R. 2016a. Malaria in Uganda: school-based rapid diagnostic testing and treatment. International Journal of Epidemiology, 45(6), December:1759-1762. [https://doi.org/10.1093/ije/dyw262].

6 Cohee, L.M., Chilombe, M., Ngwira, A., Jemu, S.K., Mathanga, D.P., Laufer, M.K. 2018. Pilot study of the addition of mass treatment for malaria to existing school-based programs to treat neglected tropical diseases. The American Journal of Tropical Medicine and Hygiene, 98(1):95-99. [https://doi.org/10.4269/ajtmh.17-0590]. 
interventions delivered through schools, but there remains no consensus as to the optimal intervention strategy. ${ }^{7}$

Despite being preventable, detectable and curable, malaria remains one of the leading causes of mortality due to infectious disease; Plasmodium falciparum malaria is a key global driver of mortality and morbidity with people in sub-Saharan Africa most affected. ${ }^{8}$ The burden of disease is highest in children, although the prevalence of Plasmodium falciparum in African school-age children varies widely depending on the level of transmission, setting and season. Houngbedji and colleagues (N’Dri, Hürlimann, Yapi, Silué, Soro, Koudou, Acka, Assi, Vounatsou, N'Goran, Fantodji, Utzinger \& Raso, 2015) found seven out of ten school-aged children in Côte d'Ivoire infected with Plasmodium falciparum in a national, crosssectional study of more than 5000 children from 93 schools, based on combined microscopy results and rapid diagnostic testing. ${ }^{9}$ Nankabirwa and colleagues (Brooker, Clarke, Fernando and Gitonga, 2014) reported that 14-64 per cent of school-age children in Uganda are parasitemic at any one time. ${ }^{10}$ In Mali, malaria accounts for 36 per cent of medical consultations in school-aged children during the peak transmission season. ${ }^{11}$ There is broad agreement that school-age children represent an underappreciated reservoir of malaria infection, have less exposure to antimalarial interventions, and malaria control and elimination strategies need to expand to include this age group. ${ }^{12}$

7 Temperley et al., 2008; Drake, T.L., Okello, G., Njagi. K, Halliday, K.E., Jukes., Mangham, L. \& Brooker, S. 2011. Cost analysis of school-based intermittent screening and treatment of malaria in Kenya. Malaria Journal, 10(273). [https://doi. org/10.1186/1475-2875-10-273]; Drake et al., 2011.

8 Bell et al., 2016; WHO. 2014. World Malaria Report. WHO Global Malaria Programme. [https://bit.ly/2Yx75gK] (Accessed 6 December 2019).

9 Houngbedji, C.A., N’Dri, P.B., Hürlimann, E., Yapi, R.B., Silué, K.D., Soro, G., Koudou, B.G., Acka, C.A., Assi, S.B., Vounatsou, P., N'Goran, E.K., Fantodji, A., Utzinger, J. \& Raso, G. 2015. Disparities of Plasmodium falciparum infection, malariarelated morbidity and access to malaria prevention and treatment among school-aged children: a national cross-sectional survey in Côte d'Ivoire. Malaria Journal, 14(7). [https://doi.org/10.1186/1475-2875-14-7].

10 Nankabirwa et al., $2014 \mathrm{a}$.

11 Barger, B., Maiga, H., Traore, O.B., Tekete, M., Tembine, I., Dara, A., Traore, Z.I., Gantt, S., Doumbo, O.K., Djimde, A.A. 2009. Intermittent preventive treatment using artemisinin-based combination therapy reduces malaria morbidity among school-aged children in Mali. Tropical Medicine \& International Health, 14(7):784-791. [https://doi. org/10.1111/j.1365-3156.2009.02294.x].

12 Walldorf, J.A., Cohee, L.M., Coalson, J.E., Bauleni, A., Nkanaunena, K., Kapito-Tembo, A., Seydel, K.B., Ali, D., Mathanga, D., Taylor, T.E., Valim, C. \& Laufer, M.K. 2015. 
Delay in the treatment of fever is a potent obstacle to the goal of achieving a reduction in malaria mortality. ${ }^{13}$ Failure to provide WHO-recommended diagnosis and therapy leads to poor disease management, in turn contributing to a cycle of poverty in affected communities. ${ }^{14}$ Lack of access to early and accurate diagnosis is common; studies indicate that in sub-Saharan Africa less than 50 per cent of sick, febrile children receive artemisinin combination therapy within 24 hours. ${ }^{15}$ Factors limiting children receiving an accurate diagnosis and prompt treatment include:

access (distance to a clinic and a lack of parental awareness of need); cost (of prescribed medication, time away from livelihood, and transport); uncertain availability of rapid diagnostic testing diagnostics and artemisinin combination therapy at government clinics;

inadequate numbers of skilled staff;

variations in the quality of health care services;

preference for traditional practices; and

poor prescribing habits. ${ }^{16}$

School-age children are a reservoir of malaria infection in Malawi. PLoS One, 10(7): e0134061. [https://doi.org/10.1371/journal.pone.0134061].

13 White, N., Pukrittayakarnee, S., Hien, T.T., Faiz, M.A., Mokuolu, O.A. \& Dondorp, A.M. 2014. Malaria. The Lancet. 383(9918):723-735. [https://doi.org/10.1016/S0140-6736(13)60024-0].

14 Amexo, M., Tolhurst, R., Barnish, G., Bates, I. 2004. Malaria misdiagnosis: effects on the poor and vulnerable. The Lancet, 364(9448):1896-1898. [https://doi.org/10.1016/S01406736(04)17446-1]; Sachs, J. \& Malaney, P. 2002. The economic and social burden of malaria. Nature, 415(6872):680. [https://doi.org/10.1038/415680a].

15 Macnab, A.J., Mutabazi, S., Mukisa, R., Eliab, A., Kigozi, H. \& Steed, R. 2016b. The impact on absence from school of rapid diagnostic testing and treatment for malaria. International Journal of Learning, Teaching and Educational Research, 15(7):20-37. [https://bit.ly/3jaiQS1]; Simba, D.O., Warsame, M., Kakoko, D., Mrango, Z., Tomson, G., Premji, Z. \& Petzold, M. 2010. Who gets prompt access to artemisininbased combination therapy? A prospective community-based study in children from rural Kilosa, Tanzania. PLoS One, 5(8):e12104. [https://doi.org/10.1371\%2Fjournal. pone.0012104]; Tipke, M., Louis, V.R., Yé, M., De Allegri, M., Beiersmann, C., Sié, A., Mueller, O. \& Jahn, A. 2009. Access to malaria treatment in young children of rural Burkina Faso. Malaria Journal, 8(266). [https://doi.org/10.1186/1475-2875-8-266].

16 Macnab et al., 2016b; Mutabingwa, T.K. 2005. Artemisinin-based combination therapies (ACTs): best hope for malaria treatment but inaccessible to the needy! Acta Tropica, 95(3):305-301. [https://doi.org/10.1016/j.actatropica.2005.06.009]; Rutebemberwa, E., Kallander, K., Tomson, G., Peterson, S. \& Pariyo, G. Determinants of delay in care- 
Compared to younger children, school-age children are brought less often for treatment, and more often to unreliable treatment sources. ${ }^{17}$

Global efforts to increase access to rapid diagnostic testing and artemisinin combination therapy have made an impact following WHO endorsement. ${ }^{18}$ Diagnostic testing in the public sector in sub-Saharan Africa increased from 36 per cent of suspected cases tested in 2005 to 65 per cent in 2014, with rapid diagnostic testing accounting for 71 per cent of tests. ${ }^{19}$ Rapid diagnostic testing is increasingly being incorporated into national malaria management guidelines as an aid to diagnosis in resource-poor settings. The accuracy of rapid diagnostic testing and efficacy of artemisinin combination therapy are good, so effective ways to deliver these agents where they are needed is now key. ${ }^{20}$ Initiatives often generated by government agencies have explored ways to make rapid diagnostic testing more available and promote improved use of artemisinin combination therapy, predominantly through stocks in pharmacies and private medical clinics. ${ }^{21}$ Availability in rural areas, however, often remains low despite the heightened need.

seeking for febrile children in eastern Uganda. Tropical Medicine \& International Health, 14(4):4729. [https://doi.org/10.1111/j.1365-3156.2009.02237.x].

17 Walldorf et al., 2015.

18 Gitonga, C., Amin, A., Ajanga, A., Kangwana, B., Noor, A. \& Snow, R.W. 2008. The use of artemether-lumefantrine by febrile children following national implementation of a revised drug policy in Kenya. Tropical Medicine \& International Health, 13(4):487-494. [https://doi.org/10.1111\%2Fj.1365-3156.2008.02026.x].

19 WHO. 2015. World Malaria Report. WHO Global Malaria Programme. [https://bit.ly/3gn8BYL] (Accessed 6 December 2019).

20 Rutebemberwa et al., 2009; Mikhail, A.F., Leslie, T.J., Mayan, M.I., Zekria, R., Mohammad, N., Hasanzai, M.A., Safi, N., Whitty, C.J. \& Rowland, M. 2011. Field trial of three different Plasmodium vivax-detecting rapid diagnostic tests with and without evaporative cool box storage in Afghanistan. Malaria Journal, 10(169).

[https://doi.org/10.1186/1475-2875-10-169]; Khatib, R.A., Selemani, M., Mrisho, G.A., Masanja, I.M., Amuri, M., Njozi, M.H., Kajungu, D., Kuepfer, I., Abdulla, S.M. \& De Savigny, D. 2013. Access to artemisinin-based anti-malarial treatment and its related factors in rural Tanzania. Malaria Journal, 12(155).

[https://doi.org/10.1186/1475-2875-12-155].

21 Mbonye, A.K., Magnussen, P., Lai, S., Hansen, K.S., Cundill, B., Chandler, C., Clarke, S.E. 2015. A cluster randomized trial introducing rapid diagnostic tests in registered drug shops in Uganda: Impact on appropriate treatment of malaria. PLoS One, 10(7):e0129545. [https://doi.org/10.1371/journal.pone.0129545]; Visser, T., Bruxvoort, K., Maloney, K., Leslie, T., Barat, L.M., Allan, R., Ansah, E.K., Anyanti, J., Boulton, I., Clarke, S.E., Cohen, J.L., Cohen, J.M., Cutherell, A., Dolkart, C., Eves, K., Fink, G., Goodman, C., Hutchinson, E., Lal, S., Mbonye, A., Onwujekwe, O., Petty, N., Pontarollo, J., Poyer, S., Schellenberg, D., Streat, E., Ward, A., Wiseman, V., Whitty, C.J., Yeung, S., Cunningham, J. \& Chandler, C. 2017. Introducing malaria rapid 
To date, endorsement of school-based use of rapid diagnostic testing or artemisinin combination therapy has been lacking, and innovative national strategies are needed to achieve improved access and utilisation. ${ }^{22}$

A Lancet review summarises the decline of the burden of malaria in sub-Saharan Africa with the scaling up of prevention, diagnosis, and treatment. Studies were included if they reported at least two years of data on malaria-specific indicators (clinical or slide diagnosed case numbers, incidence, prevalence, or malariaspecific mortality) in a population of more than 1000 people. ${ }^{23}$ Malaria mortality is concentrated among children, ${ }^{24}$ and inherently however, remains linked to poverty. ${ }^{25}$ In countries where it is endemic malaria is reported to be the main reason a school-aged child will die; in parallel, an important measure of the morbidity malaria causes is that infection is the principal reason why a child will be absent from school. ${ }^{26}$

School teachers recognise the negative impact of malaria on pupil's health and the adverse effects of infection on their ability to learn; they see first-hand the impact on school-age children's performance documented in a structured review (Nankabirwa et al., 2014a). ${ }^{27}$ They know infection prevents children attending school, that sub-optimal treatment leaves residual malaise that negatively impacts a child's capacity to be fully present in class, and repeated infection can permanently compromise a child's academic potential due to neurological complications. ${ }^{28}$ The

diagnostic tests in private medicine retail outlets: a systematic literature review. PLoS One, 12(3):e0173093. [https://doi.org/10.1371/journal.pone.0173093].

22 Houngbedji et al., 2015; Mutabingwa, 2005; Khatib et al., 2013.

23 O’Meara, W.P., Mangeni, J.N., Steketee, R., Greenwood, B. 2010. Changes in the burden of malaria in sub-Saharan Africa. The Lancet Infectious Diseases, 10(8):545-55.

[https://doi.org/10.1016/S1473-3099(10)70096-7].

24 WHO, 2014; Sachs \& Malaney, 2002.

25 Marmot et al., 2008.

26 Brooker, S., Guyatt, H., Omumbo, J., Shretta, R., Drake, L. \& Ouma, J. 2000. Situation analysis of malaria in school-aged children in Kenya-what can be done? Parasitol Today, 16(5):183-186. [https://doi.org/10.1016/s0169-4758(00)01663-x]; Jukes, M.C.H., Drake, L.J. \& Bundy, D.A.P. 2008. Challenges for child health and nutrition. In: Jukes, M.C.H., Drake, L.J. \& Bundy, D.A.P., (eds). 2008. School health, nutritional and education for all: levelling the playing field. Cambridge, USA: CABI Publishing. pp.11-31. [https://bit.ly/3gpMbG8]; Clarke, S.E., Brooker, S., Njagi, J.K., Njau, E., Estambale, B., Muchiri, E. \& Magnussen, P. 2004. Malaria morbidity among school children living in two areas of contrasting transmission in western Kenya. The American Journal of Tropical Medicine and Hygiene, 71(6):732-738. [https://doi.org/10.4269/ajtmh.2004.71.732].

27 Nankabirwa et al., 2014a.

28 Kihara, M., Carter, J.A., Newton, C.R. 2006. The effect of Plasmodium falciparum 
review emphasises that due to current trends in lowering malaria transmission, and the tendency for school-age children to acquire immunity later in life, this age group faces an increase in the incidence of both uncomplicated and severe malaria in previously high endemic areas. ${ }^{29}$ Hence, it needs special measures to protect them against malaria, with more programme implementation and innovative measures, both important. Ongoing research and evaluation are also needed to build the evidence base of 'what works and why', and where such interventions are most effective. ${ }^{30}$

A social factor relevant to school-based health promotion in Africa, and most other low- and middle-income countries, is that children found to be sick at school are generally sent home by teachers. ${ }^{31}$ This action devolves key care decisions to parents, which is problematic in malaria-endemic areas, as many families lack knowledge about appropriate care for children with probable malaria. This situation often contributes to morbidity, as in many cases, appropriate diagnosis and timely treatment do not occur. ${ }^{32}$

The WHO advocates early, accurate diagnosis of malaria and prompt, effective and affordable treatment within 24 hours of the onset of illness. ${ }^{33}$ Validated measures to do this exist, but in most low- and middle-income countries, the health resources necessary are limited and are especially scarce in rural and low resource communities. The fact that malaria symptoms are not specific is an additional factor, as a reliable diagnosis cannot be made based on history and examination

on cognition: a systematic review. Tropical Medicine \& International Health, 11(4):386-397. [https://doi.org/10.1111/j.1365-3156.2006.01579.x]; Fernando, S.D., Gunawardena, D.M., Bandara, M.R., De Silva, D., Carter, R., Mendis, K.N. \& Wickremasinghe, A.R. 2001. The impact of repeated malaria attacks on the school performance of children. The American Journal of Tropical Medicine and Hygiene, 69(6):582-588. [https://doi.org/10.4269/ajtmh.2003.69.582]; Holding, P.A. \& Snow, R.W. 2001. Impact of Plasmodium falciparum malaria on performance and learning: Review of the evidence. The American Journal of Tropical Medicine and Hygiene, 64(Supplement 1):68-75. [https://doi.org/10.4269/ajtmh.2001.64.68].

29 Nankabirwa et al., 2014a.

30 Ibid.

31 Macnab et al., 2016a. Macnab, A.J., Stewart, D. \& Gagnon, F. 2014a. Health Promoting Schools: Initiatives in Africa. Health Education, 114(4), May:246-259. [https://doi.org/10.1108/HE-11-2013-0057].

32 Macnab et al., 2016b; Källander, K., Nsungwa-Sabiiti, J. \& Peterson, S. 2004. Symptom overlap for malaria and pneumonia-policy implications for home management strategies. Acta Tropica, 90(2):211-214. [https://doi.org/10.1016/j.actatropica.2003.11.013].

33 WHO, 2014. 
alone. ${ }^{34}$ Even using a WHO-derived diagnostic algorithm designed for Community Health Workers, trained teachers in Ghana could not match all presumptive malaria to the case definition..$^{35}$ This difficulty with diagnosing malaria on clinical grounds, lack of knowledge about the need for care, and limited facilities all contribute to morbidity and mortality. Hence, simple, accurate and inexpensive diagnostic tools, health education and the wider availability of effective therapy are needed to reduce the impact of malaria on children. ${ }^{36}$

Malaria health promotion initiatives centred on schools that increase access to effective diagnostic and treatment measures are an example of the type of innovative, content specific intervention called for by the WHO Commission on Social Determinants of Health to support healthy behaviours. They empower young people to take control of their lives. ${ }^{37}$ Such 'task-shifting' to school-based programmes can also increase the provision of other essential health services. ${ }^{38}$ Robust precedents for such approaches exist in successful, valuable and costeffective teacher-administered health programmes in schools in low- and middleincome countries including the provision of intermittent anti-malarial therapy in Kenya, prophylactic chloroquine in Sri Lanka, and nationwide anti-helminth treatment in Uganda, and Ghana. ${ }^{39}$ Importantly, cost-benefit analysis shows that

34 Källander, Nsungwa-Sabiiti \& Peterson, 2004.

35 WHO. 1992. Malaria: A training guide for district health workers on malaria control in tropical Africa. [https://bit.ly/32krkPB]; Afenyadu, G.Y., Agyepong, I.A., Barnish, G. \& Adjei, S. 2005. Improving access to early treatment of malaria: a trial with primary school teachers as care providers. Tropical Medicine \& International Health, 10(10):1065-1072. [https://doi.org/10.1111/j.1365-3156.2005.01484.x].

36 Nankabirwa et al., 2014a; Bell et al., 2016.

37 Macnab, Stewart \& Gagnon, 2014a; WHO. 2008. Closing the gap in a generation: health equity through action on the social determinants of health. Commission on Social Determinants of Health - Final Report. [https://bit.ly/2QxIlAF]; Sachs \& Malaney, 2002.

38 Agyepong, I.A., Sewankambo, N., Binagwaho, A., Coll-Seck, A.M., Corrah, T., Ezeh, A., Fekadu, A., Kilonzo, N., Lamptey, P., Masiye, F., Mayosi, B., Mboup, S., Muyembe, J.J., Pate, M., Sidibe, M., Simons, B., Tlou, S., Gheorghe, A., Legido-Quigley, H., McManus, J., Ng, E., O’Leary, M., Enoch, J., Kassebaum, N. \& Piot, P. 2017. The path to longer and healthier lives for all Africans by 2030: The Lancet Commission on the future of health in sub-Saharan Africa. The Lancet, 390(10114):2803-2859. [https://doi.org/10.1016/S0140-6736(17)31509-X].

39 Temperley et al., 2008; Okello, G., Ndegwa, S.N., Halliday, K.E., Hanson, K., Brooker, S.J., Jones, C. 2012. Local perceptions of intermittent screening and treatment for malaria in school children on the south coast of Kenya. Malaria Journal, 11(185). [https://doi.org/10.1186/1475-2875-11-185]; Fernando, D., De Silva, D., Carter, R., Mendis, K.N. \& Wickremasinghe, R. 2006. Randomized, double-blind, placebocontrolled, clinical trial of the impact of malaria prevention on the educational attainment 
health programme delivery costs can be reduced by having teachers implement such programmes. ${ }^{40}$

\section{Burden of disease in school-age children}

While the overall incidence and number of deaths from malaria are decreasing worldwide, the disease is still a major cause of mortality and morbidity among children. ${ }^{41}$

\section{Mortality}

Fifty per cent of deaths in school-aged children (between five and 14 years) are estimated to be due to malaria in Africa. ${ }^{42}$ Cerebral malaria (severe Plasmodium falciparum malaria presenting with neurological symptoms, including coma (Glasgow coma scale less than 11, or a Blantyre coma scale less than three), or with a coma that lasts more than 30 minutes after a seizure)), affects more than half a million children per year in Africa and kills between 10-40 per cent of those infected. ${ }^{43}$ Poor health, poverty, lack of knowledge at a community level and limited access to care are contributory factors that increase a child's risk. ${ }^{44}$

\section{Morbidity}

Studies in Africa and Thailand indicate that malaria causes five-eight per cent of all school absenteeism. Reports from Kenya indicate that primary school students

of school children. The American Journal of Tropical Medicine and Hygiene, 74(3):386-393. [http://www.ajtmh.org/content/journals/14761645]; Brooker, S., Kabatereine, N.B., Fleming, F. \& Devlin, N. 2008. Cost and cost-effectiveness of nationwide school-based helminth control in Uganda: intra-country variation and effects of scaling-up. Health Policy Plan, 23(1):24-35. [https://doi.org/10.1093/heapol/czm041]; Opoku, E.C., Olsen, A., Browne, E., Hodgson, A., Awoonor-Williams, J.K., Yelifari, L., Williams, J. \& Magnussen, P. 2016. Impact of combined intermittent preventive treatment of malaria and helminths on anaemia, sustained attention, and recall in northern Ghanaian schoolchildren. Global Health Action, 9:32197. [https://doi.org/10.3402/gha.v9.32197].

40 Drake et al., 2011; Fernando et al., 2006; Laxminarayan, R., Chow, J. \& ShahidSalles, S.A. 2006. Intervention Cost-Effectiveness: Overview of Main Messages. In: Breman, J.G., Measham, A.R., Alleyne, G., Jamison, D.T., Claeson, M., Evans, D.B., Jha, P., Mills, A. \& Musgrove, P. (eds). Disease Control Priorities for Developing Countries. Oxford: Oxford University Press. pp.35-86.

41 WHO, 2015.

42 Nankabirwa et al., $2014 \mathrm{a}$.

43 WHO, 2019; Holding \& Snow, 2001.

44 Houngbedji et al., 2015; Sachs \& Malaney, 2002; Mutabingwa, 2005. 
miss 11 per cent of school days per year because of malaria, and secondary students can miss 4.3 per cent of school days. ${ }^{45}$ Such data equate with malaria being the cause of approximately 50 per cent of all preventable absenteeism. ${ }^{46}$ Hence, reducing morbidity offers real potential for school children to gain increased educational benefits just from improved attendance.

However, the adverse effects on schooling go far beyond compromised attendance. Even an attack of uncomplicated malaria can cause significant short-term impairment of cognitive performance; the impairment a child experiences often persists for around two weeks; and adverse effects appear to be cumulative with repeated attacks. ${ }^{47}$ Where the principal infecting agent is Plasmodium falciparum, the infection can be associated with permanent loss of cognitive and fine motor function from complications, especially where the diagnosis is delayed and/or treatment is sub-optimal. ${ }^{48}$

In the Brazilian Amazon (where the infection is predominantly with Plasmodium vivax) multivariate analysis indicates that presenting with at least one episode of malaria, independently, predicts a poor performance at school. ${ }^{49}$ In Asian studies

45 Leighton, C. \& Foster, R. 1993. Economic impacts of malaria in Kenya and Nigeria. Major Applied Research Paper No. 6. Health Financing and Sustainability (HFS) Project. Medical Services Corporation International. [https://bit.ly/3aQ55ow].

46 Fernando et al., 2001; Sachs \& Malaney, 2002; Fernando, D., De Silva, D. \& Wickremasinghe, R. 2003. Short-term impact of an acute attack of malaria on the cognitive performance of schoolchildren living in a malaria-endemic area of Sri Lanka. Transactions of The Royal Society of Tropical Medicine and Hygiene, 97(6):633-639. [https://doi.org/10.1016/s0035-9203(03)80093-7].

47 Kihara, Carter \& Newton, 2006; Fernando et al., 2001.

48 Boivin, M.J., Bangirana, P., Byarugaba, J., Opoka, R.O., Idro, R., Jurek, A.M. \& John, C.C. 2007. Cognitive impairment after cerebral malaria in children: a prospective study. Pediatrics, 119(2):e360-366. [https://doi.org/10.1542/peds.2006-2027];

Fernando, S.D., Rodrigo, C. \& Rajapaske, S. 2010. The 'hidden' burden of malaria: cognitive impairment following infection. Malaria Journal, 9(366).

[https://doi.org/10.1186/1475-2875-9-366]; Birbeck, G.L., Molyneux, M.E., Kaplan, P.W., Seydel, K.B., Chimalizeni, Y.F., Kawaza, K. \& Taylor, T.E. 2010. Blantyre malaria project epilepsy study (BMPES) of neurological outcomes in retinopathy positive pediatric cerebral malaria survivors: a prospective cohort study. The Lancet Neurology, 9(12):1173-1181. [https://doi.org/10.1016/S1474-4422(10)70270-2]; Thuilliez, J., Sissoko, M.S., Toure, O.B., Kamate, P., Berthelemy, J. \& Doumbo, O.K. 2010. Malaria and primary education in Mali: a longitudinal study in the village of Doneguebougou. Social Science \& Medicine, 71(2):324-334. [https://doi.org/10.1016\%2Fj. socscimed.2010.02.027].

49 Vitor-Silva, S., Reyes-Lecca, R.C., Pinheiro, T.R. \& Lacerda, M.V. 2009. Malaria is associated with poor school performance in an endemic area of the Brazilian Amazon. 
in low transmission areas, most indices of performance-tested at school entry in a cross-sectional study were poorer as the number of malaria infections experienced by a child increased, after controlling for confounding factors. ${ }^{50}$ School performance of six to 14-year-old children was related to the number of previous episodes of malaria; acute uncomplicated attacks caused short-term learning difficulty for a week or more, and the effects were compounded by subsequent attacks. ${ }^{51}$ Thus, the combined effects of absence, sub-optimal convalescent health and long-term neurological compromise can adversely affect performance in class and pass rates, lead to the need for a child to repeat grades, and even cause children to drop out of school altogether.

The exact mechanisms involved in causing long-term detriment to cognitive development and learning ability are debated. ${ }^{52}$ There is a clear relationship between infection intensity and the magnitude of the adverse cognitive effect (i.e. the higher the parasitemia, the higher the impact on the cognitive score).${ }^{53}$ Thuilliez and colleagues (Sissoko, Toure, Kamate, Berthelemy and Doumbo, 2010) provide an excellent schematic that illustrates the probable effects and pathways based on a series of studies examining the cognitive function and school performance depending on falciparum and vivax malaria and evaluating malaria prevention on educational achievement since $2003 .{ }^{54}$

Children who survive 'cerebral' malaria, frequently show clinical evidence of neurological sequelae, including impaired ability to carry out executive functions (e.g. planning, initiating and executing executive tasks), and behavioural disorders that compromise their ability to engage fully in class. Kenyan school children hospitalised for cerebral malaria were 4.5 times more likely to have mild-tosevere learning difficulties three-four years later, even though half of them had no neurological problems at the time of admission..$^{55}$ The risk of impaired intellectual function is increased where seizures accompany clinical malaria.

Malaria Journal, 8(230). [https://doi.org/10.1186/1475-2875-8-230].

50 Fernando, S.D., Wickremasinghe, R., Mendis, K.N. \& Wickremasinghe, A.R. 2003. Cognitive performance at school entry of children living in a malaria endemic area in Sri Lanka. Transactions of The Royal Society of Tropical Medicine and Hygiene, 97:161-165. [https://doi.org/10.1016/s0035-9203(03)90107-6].

51 Fernando et al., 2001.

52 Ibid.; Holding \& Snow, 2001.

53 Thuilliez et al., 2010.

54 Ibid.

55 Holding \& Snow, 2001. 
Thus, prolonged, severe and repeated illness can reduce both the opportunity and the ability of a school-age child to learn. Consequently, there is great potential worldwide for both health and educational benefits to be accrued, where a reduction in child morbidity due to malaria can be achieved.

\section{Historic interventions for malaria}

Recognition that the use of malaria suppressive drugs for special groups might be beneficial existed as early as the 1920s. ${ }^{56}$ The use of quinine in the Gold Coast (Ghana) was reported in 1925 but achieved little success. ${ }^{57}$ Pyrimethamine, the first synthetic antimalarial tried, controlled malaria in children in Nigeria (1951); success was achieved with this agent subsequently in group treatment in Haute Volta. ${ }^{58}$ In a two-year study using prophylaxis in 277 Nigerian children aged five to 10 years (1956) also identified benefits related to better general health, as average weight gain in treated children was significantly higher than that of untreated children. ${ }^{59}$ Unpublished data included in a 1955 report by Colbourne indicates that chloroquine proved to be an effective suppressive agent in a group of adolescents in the Gold Coast in $1952 .^{60}$

Colbourne also used a combination of amodiaquine and pyrimethamine to suppress malaria in seven-year-old children in an Accra school. At the beginning of each term, 176 children received amodiaquine (to clear parasitemia), and they weekly received pyrimethamine (to suppress malaria). Seventy-six 'controls' received dummy tablets. ${ }^{61}$ Interestingly, this study included the first observation that freedom from malaria resulted in the reduction of school absenteeism due to sickness by approximately 50 per cent. Reduction in the duration of absence from school is now an accepted surrogate measure for morbidity from malaria. Of note, Colbourne's initial estimate that five-six school days were saved per child

56 Colbourne, M.J. 1955. The effect of malaria suppression in a group of Accra school children. Transactions of The Royal Society of Tropical Medicine and Hygiene, 49(4):556-569. [https://doi.org/10.1016/0035-9203(55)90058-4].

57 Magill, E.M. 1924. Report on medical inspection of school children in Accra during 1923. Government Sessional Paper No. 11 of 1924-5. Accra: Government Printers, 5.

58 Masseguin, A. \& Palinacci, A. 1953. First Results of Chemoprophylaxis of Malaria with Malocide (Pyrimethamine) in Children in Upper Volta. Bulletin de la Société de Pathologie Exotique, 46(5):673-676.

59 Archibald, H.M. \& Bruce-Chwatt, L.J. 1956. Suppression of malaria with pyrimethamine in Nigerian schoolchildren. Bulletin of the WHO, 15(3-5):775-784.

[https://www.ncbi.nlm.nih.gov/pmc/articles/PMC2538299/].

60 Colbourne, 1955.

61 Ibid. 
with malaria suppression, is directly comparable to the finding 60 years later of a mean reduction in absence from 6.5 to less than one school day(s) when the effects of rapid diagnosis and prompt treatment were followed in school-based studies in Uganda. ${ }^{62}$

\section{School-based intervention}

\section{Health education}

The WHO has always placed community participation at the centre of its 'health for all' strategies. ${ }^{63}$ It is often teachers who identify health issues that warrant attention and seek to initiate education or skills teaching in school to address them. ${ }^{64}$ An important construct, as it makes cooperation and long-term commitment by teachers to health promotion realistic. The literature shows teachers have collaborated in programmes addressing a range of health issues; evidence which is important in the necessary dialogue about whether teachers will be motivated enough to invest the time required to help initiate and then sustain any schoolbased intervention.

Schools can be an effective and efficient way to reach a large segment of the population, as globally, more than one billion children have the potential to benefit from school-based health delivery. ${ }^{65}$ The WHO's Health-Promoting School model is an innovative approach to health promotion, and also towards attaining the UN's 17 Sustainable Development Goals; as these have the overarching aim of addressing poverty worldwide, they have relevance in the context of reducing the burden of malaria. Goals 1-6 directly address factors that contribute to health, disease and wellbeing in children (poverty, malnutrition, health, education, empowering women and girls, and water). ${ }^{66}$ The Health-Promoting School model employs multi-disciplinary strategies to engage a school community; children

62 Macnab et al., 2016a.

63 Lasker, R.D. \& Weiss, E.S. 2003. Broadening participation in community problem solving: a multidisciplinary model to support collaborative practice and research. Journal of Urban Health, 80(1):14-47. [https://doi.org/10.1093/jurban/jtg014].

64 Macnab, Stewart \& Gagnon, 2014a.

65 WHO, 2013. What is a health promoting school? [https://bit.ly/31lOvdn] (Accessed 10 December 2018); Macnab, A.J. 2013. The Stellenbosch consensus statement on Health Promoting Schools. Global Health Promotion, 20(1):78-81.

[https://doi.org/10.1177/1757975912464252].

66 Costanza, R., Daly, L., Fioramonti, L. \& Giovannini, E., Kubiszewski, I., Mortensen, L.F., Pickett, K.E., Ragnarsdottir, K.V., De Vogli, R., Wilkinson, R. 2016. Modelling and measuring sustainable wellbeing in connection with the UN Sustainable 
readily assimilate 'knowledge' and 'skills;' and the WHO's overarching objective is to generate life-long learning that positively influences the social determinants of health. ${ }^{67}$ The WHO now endorses school programmes as a way to address specific health challenges worldwide. ${ }^{68}$

In the author's opinion, the inclusion of education on malaria in all schools in endemic areas should be the norm. Educational and protective strategies can be delivered in parallel and are potentially synergistic. In the author's experience, children broadly educated about malaria are all the more likely to recognise the relevance of preventive strategies like indoor spraying and insecticide-treated bed nets. They can aid community adoption of vector control interventions (novel or non-insecticide-based approaches offer particular promise), and potentially become involved in malaria vaccine roll-out, rightly heralded as a paradigm shift with huge implications for the protection of school children. ${ }^{69}$ Thus far, the programmes to immunise are not school-based.

Current data on the use of insecticide-treated bed nets suggest focused school-based education could impact prevention. In most low- and middle-income countries less than 50 per cent of households own a mosquito net despite promotional programmes; even when nets are present many are untreated with insecticide, and most children do not sleep under insecticide-treated bed nets. ${ }^{70} \mathrm{~A}$ large cross-

Development Goals. Ecological Economics, 130:350-355. [https://doi.org/10.1016/j. ecolecon.2016.07.009].

67 Macnab, 2013; Viner, R.M., Ozer, E.M., Denny, S., Marmot, M., Resnick, M., Fatusi, A. \& Currie, C. 2012. Adolescence and the social determinants of health. The Lancet, 379(9826):1641-1652. [https://doi.org/10.1016/S0140-6736(12)60149-4].

68 WHO, 2008; Sachs \& Malaney, 2002; Tang, K., Nutbeam, D., Aldinger, C. St Leger, L., Bundy, D., Hoffmann, A.M., Yankah, E., McCall, D., Buijs, G., Arnaout, S., Morales, S., Robinson, F., Torranin, C., Drake, L., Abolfotouh, M., Whitman, C.V., Meresman, S., Odete, C., Joukhadar, A.H., Avison, C., Wright, C., Huerta, F., Munodawafa, D., Nyamwaya, D. \& Heckert, K. 2008. Schools for health, education and development: a call for action. Health Promotion International, 24(1):68-77. [https://doi.org/10.1093/heapro/dan037].

69 Miller, M.W. \& Tren, R. 2012. Implications of public-health insecticide resistance and replacement costs for malaria control: challenges and policy options for endemic countries and donors. Research and Reports in Tropical Medicine, 3:1-19. [https://doi. org/10.2147\%2FRRTM.S30914]; Greenwood, B., Dicko, A., Sagara, I., Zongo, I., Tinto, H., Cairns,M., Kuepfer, I., Milligan, P., Ouedraogo, J., Doumbo, O. \& Chandramohan, D. 2017. Seasonal vaccination against malaria: a potential use for an imperfect malaria vaccine. Malaria Journal, 16(182). [https://doi.org/10.1186/s12936-017-1841-9].

70 Walldorf et al., 2015; Macnab et al., 2016b; Swana, E.K., Makan, G.Y., Mukeng, C.K., Mupumba, H., Kalaba, G.M., Luboya, O.N., Bangs, M.J. 2016. Feasibility and 
sectional study in Malawi found that there were significant differences in net use based on age in areas where school-age children had the highest prevalence of malaria, with only 57 per cent of school children reported to use an insecticidetreated bed net, compared to 74 per cent of adults and 76 per cent of younger children. ${ }^{71}$ A study based on national survey data from 18 malaria-endemic areas in Africa identified similar net use patterns. ${ }^{72}$ Recognising that a reduction in all-cause mortality among children of up to 60 per cent has been realised when insecticide-treated bed nets are used in areas of stable endemic transmission, these data underscore the need for school-based programmes that improve knowledge and practices related to prevention. ${ }^{73}$

Schools can also play a vital role in ensuring that pupils understand the importance of obtaining rapid access to correct diagnosis and effective treatment. ${ }^{74}$ The author agrees with other authors that such knowledge must be regarded as essential and that there are many simple, effective and inexpensive ways to give children this knowledge through additions to the curriculum. However, health education must engage pupils for these messages to have an impact. The shared facts and how they are taught must resonate and have 'relevance' for the learner if what is learned is to lead to a behavioural change. The incentive to educate effectively is research showing that adolescents tend to retain knowledge that resonates culturally and which they perceive to be personally and socially relevant; that effective learning can translate into positive behaviours, and many of these persist into adult life. ${ }^{75}$

Motivated teachers seek out novel approaches to engaging their pupils; for example, implementing a clean-up programme around the school where pupils collect discarded plastic bottles, bags and bottle caps, provides evidence-based learning

implementation of community-based malaria case management with integrated vector control in the Democratic Republic of Congo. Malaria Journal, 15(413).

[https://doi.org/10.1186/s12936-016-1475-3].

71 Walldorf et al., 2015.

72 Noor, A.M., Kirui, V.C., Brooker, S.J. \& Snow, R.W. 2009. The use of insecticide treated nets by age: implications for universal coverage in Africa. BMC Public Health, 9(369). [https://doi.org/10.1186/1471-2458-9-369].

73 Nankabirwa et al., $2014 \mathrm{a}$.

74 Brooker, S., Guyatt, H., Omumbo, J., Shretta, R., Drake, L., Ouma, J. 2000. Situation analysis of malaria in school-aged children in Kenya-what can be done? Parasitol Today, 16(5):183-186. [https://doi.org/10.1016/s0169-4758(00)01663-x].

75 Marmot et al., 2008; Viner et al., 2012; Airhihenbuwa, C.O., Makoni, S., Iwelunmor, J. \& Munodawafa, D. 2014. Sociocultural Infrastructure: Communicating Identity and Health in Africa. Journal of Health Communication International Perspectives, 19(1):1-5. [https://doi.org/10.1080/10810730.2013.868767]. 
when pupils understand these items offer breeding habitat for mosquito larvae, and a way to encourage effective prevention practices. ${ }^{76}$

Worldwide it is still commonplace to find children lack even the most basic knowledge about malaria. In a recent survey in Ugandan primary schools, only one in five children knew what caused malaria, or if it can be prevented, what signs and symptoms suggest infection, and what can be done to treat an infection. ${ }^{77}$

Evidence that the broader community also lacks essential knowledge comes from data showing how small a proportion of sick, febrile children with presumptive malaria are taken for appropriate care. Simba and colleagues (Warsame, Kakoko, Mrango, Tomson, Premji and Petzold, 2010) identified that less than half (44.8 per cent) were taken to government facilities, and only 37.6 per cent had prompt access to artemisinin combination therapy. ${ }^{78}$ The author's experience is similar - only one in four children ( 26 per cent) sent home from schools with a febrile illness compatible with malaria, received management meeting the WHO criteria. The majority (42 per cent) were only given an anti-pyretic, and care of the remainder included local herbal remedies (19 per cent), being taken to church (eight per cent), or visiting a traditional healer (six per cent). ${ }^{79}$

There is growing evidence that where children receive sufficient guidance, they can act as agents for change in both the school and their local community. ${ }^{80}$ Knowledge and skills learned from effective school-based health education 'ripple' out to involve siblings and parents. ${ }^{81}$ Importantly, this willingness to share learned

76 De Silva, P.M. \& Marshall, J.M. 2012. Factors contributing to urban malaria transmission in sub-Saharan Africa: a systematic review. Journal of Tropical Medicine, 2012(819563). [https://doi.org/10.1155/2012/819563].

77 Macnab et al., 2016a.

78 Simba et al., 2010.

79 Macnab, A.J., Mutabazi, S., Mukisa, R., Eliab, A., Kigozi, H. \& Steed, R. 2016. The impact on absence from school of rapid diagnostic testing and treatment for malaria. International Journal of Learning, Teaching and Educational Research, 15(7):20-37. [https://bit.ly/3jaiQS1].

80 Tang et al., 2008; Simovska, V. \& Carlsson, M. 2012. Health-promoting changes with children as agents: findings from a multiple case study research. Health Education, 112(3):292-304. [https://doi.org/10.1108/09654281211217803].

81 Ayi, I., Nonaka, D., Adjovu, J.K., Hanafusa, S., Jimba, M., Bosompem, K.M., Mizoue, T., Takeuchi, T., Boakye, D.A. \& Kobayashi, J. 2010. School-based participatory health education for malaria control in Ghana: engaging children as health messengers. Malaria Journal, 9(98). [https://doi.org/10.1186/1475-2875-9-98]; Macnab, A.J., Gagnon, F. \& Stewart, D. 2014a. Health Promoting Schools: Consensus, challenges and potential. Health Education, 114(3):170-185. [https://bit.ly/34szNmL]. 
concepts and practices indicates acquisition of higher levels of health literacy. ${ }^{82}$ A Ghanaian study evaluated the impact of malaria-related participatory health education activities designed and led by teachers. Comparing communities with and without the school-based intervention, knowledge on malaria causation was significantly more accurate among pupils in the participating schools and adults in their communities; the prevalence of parasitaemia in pupils decreased from 31 per cent to 10 per cent and the number of adults who had treated a bed net with insecticide in the past six months doubled ${ }^{83}$ Similar findings in the community come from Lao People's Democratic Republic, where school-based education improved knowledge, attitudes, and practices towards malaria control. ${ }^{84}$

In keeping with other authors, in the author's opinion, the following are key components where interventions to reduce morbidly from malaria among school children are to be offered:

\section{Education}

Aim for all children to have 'health literacy' about malaria. Include key facts in the curriculum of all schools in endemic areas about the cause, prevention and clinical features of malaria, and how and why diagnosis and prompt treatment are necessary.

\section{Prevention}

Promote the use of insecticide-treated nets, so that all school-age children in malarial areas sleep under one. Children should understand vector control and contribute to local measures to clean-up garbage that provides a breeding habitat for mosquitoes.

\section{Accurate diagnosis and prompt treatment}

Advocate for the use of the $\mathrm{WHO}$-approved methods employing rapid diagnostic testing and artemisinin combination therapy, and facilitate effective intervention; in rural areas or where access to clinics and/or alternative points of care providing such services are limited, 'task-shifting' is valid, by training teachers to provide rapid diagnostic testing and artemisinin combination therapy as a school-based health service.

82 St Leger, L. 2001. Schools, health literacy and public health: possibilities and challenges. Health Promotion International, 16(2):197-205. [https://doi.org/10.1093/heapro/16.2.197].

83 Ayi et al., 2010.

84 Nonaka, D., Kobayashi, J., Jimba, M., Vilaysouk, B., Tsukamoto, K., Kano, S., Phommasack, B., Singhasivanon, P., Waikagul, J., Tateno, S. \& Takeuchi, T. 2008. Malaria education from school to community in Oudomxay province, Lao PDR. Parasitology International, 57(1):76-82. [https://doi.org/10.1016/j.parint.2007.09.005]. 


\section{Policy}

Establish local and national programmes, inter-sectoral collaboration and leadership. These are needed to highlight current epidemiological findings and research data on malaria in school-age children, and give communities specific recommendations and direction on how to address the problems faced.

\section{Malaria control strategies}

\section{Prophylaxis: regular administration of preventive drugs}

Chemoprophylaxis involves the regular administration of antimalarial drugs to those at risk of infection to maintain protective levels within the bloodstream. Prophylaxis is generally not recommended for children in malaria-endemic areas for multiple reasons; these include problems with adherence to prescribed regimens, compliance due to cost, and the significant risk of emergence, or increased risk of drug resistance. ${ }^{85}$ Over time, side-effects also preclude the use of chemoprophylactic drugs in children, particularly chloroquine.

\section{Intermittent protective treatment}

This treatment involves the periodic administration of a full therapeutic dose of an antimalarial drug or combination of drugs at predefined intervals to those at high risk of malaria, regardless of their infection status. ${ }^{86}$ For children, intermittent protective treatment is now considered a preferable alternative to chemoprophylaxis.

Three trials have involved two main approaches; seasonal malaria chemoprevention and intermittent parasite clearance. Intermittent protective treatment is one of several possible malaria control strategies which could be delivered through schools. A study reported (Fernando, De Silva, Carter, Mendis and Wickremasinghe, 2006 from Sri Lanka) is an example of comprehensive school-based intervention. In a randomised, double-blind placebo-controlled trial weekly chloroquine or placebo was given to school children (six to 12 years) for nine months. Besides a reduction

85 Temperley et al., 2008; Brooker et al., 2000.

86 Greenwood, B., Dicko, A., Sagara, I., Zongo, I., Tinto, H., Cairns, M., Kuepfer, I., Milligan, P., Ouedraogo, J., Doumbo, O. \& Chandramohan, D. 2017. Seasonal vaccination against malaria: a potential use for an imperfect malaria vaccine. Malaria Journal, 16(182). [https://doi.org/10.1186/s12936-017-1841-9]; White, N.J. 2005. Intermittent presumptive treatment for malaria. PLoS Medicine, 2(1):e3. [https://doi. org/10.1371\%2Fjournal.pmed.0020003]; Greenwood, B. 2006. Intermittent preventive treatment-a new approach to the prevention of malaria in children in areas with seasonal malaria transmission. Tropical Medicine \& International Health, 11(7):983-991. [https://doi.org/10.1111/j.1365-3156.2006.01657.x]. 
in malaria incidence in the treated group, this study also documented a significant difference in absenteeism between those receiving chloroquine versus placebo, and a marked improvement in school performance. ${ }^{87}$

Seasonal malaria chemoprevention is a control strategy recommended by the WHO targeting children living in areas of seasonal malaria transmission. Seasonal malaria chemoprevention is recommended for children under five years of age in countries where more than 60 per cent of the burden of malaria occurs in the months of the rainy season (which coincide with peak malaria transmission), a single curative dose of sulphadoxine-pyrimethamine is administered with a threeday course of amodiaquine. ${ }^{88}$

In an alternative approach in older children (six to 15 years), Thera and colleagues (Kone, Tangara, Diarra, Niare, Dembele, Sissoko and Doumbo, 2018) tested the efficacy and safety of artesunate-amodiaquine in a randomised open-label trial in Mali. ${ }^{89}$ Two hundred pupils received either a three-day course of artesunateamodiaquine during four consecutive months or no intervention. Twenty cases of uncomplicated malaria occurred in controls and three cases in the artesunateamodiaquine arm, showing a protective efficacy of 85 per cent. The authors concluded that artesunate-amodiaquine is effective and well-tolerated, and a feasible and accepted school-based seasonal malaria chemoprevention strategy. Teachers were not involved in drug administration but did facilitate contact between investigators and pupils; a close partnership was established, which added confidence that all cases of illness were captured..$^{90}$ Evidence from several African countries has also shown that seasonal malaria chemoprevention using sulphadoxine-pyrimethamine-amodiaquine is highly effective, eradicating most severe malaria, and leading to a strong reduction in Plasmodium falciparum prevalence, the incidence of uncomplicated clinical malaria, and malaria anaemia. ${ }^{91}$

87 Fernando et al., 2006.

88 WHO, 2012. WHO policy recommendation: Seasonal malaria chemoprevention (SMC) for Plasmodium falciparum malaria control in highly seasonal transmission areas of the Sahel sub-region in Africa. Global Malaria Programme Policy Recommendation. [https://bit.ly/2UljlOA].

89 Thera, M.A., Kone, A.K., Tangara, B., Diarra, E., Niare, S., Dembele, A., Sissoko, M.S. \& Doumbo, O.K. 2018. School-aged children based seasonal malaria chemoprevention using artesunate-amodiaquine in Mali. Parasite Epidemiology and Control, 3(2):96-105. [https://doi.org/10.1016/j.parepi.2018.02.001].

90 Thera et al., 2018.

91 Cairns, M., Roca-Feltrer, A., Garske, T., Cairns, M., Roca-Feltrer, A., Garske, T., Wilson, A.L., Diallo, D., Milligan, P.J., Ghani, A.C. \& Greenwood, B.M. 2012. Estimating the potential public health impact of seasonal malaria chemoprevention in African children. Nature Communications, 3:881. [https://doi.org/10.1038/ncomms1879]. 
Combining intermittent protective treatment with the expanded programme on immunisation in schools has been suggested, but data do not show significant benefit. ${ }^{92}$ Studies, where seasonal, intermittent protective treatment has proved effective in older children, include:

An open randomised controlled trial of seasonal, intermittent protective treatment among school children (six to 13 years) in Mali; 296 were randomised to one of three study arms - sulphadoxine-pyrimethamine amodiaquine or vitamin $\mathrm{C}$, with two full treatment doses, given two months apart during the season of high transmission. The incidence of clinical malaria in the sulphadoxine-pyrimethamine and amodiaquine arms was reduced by 66.6 per cent and 46.5 per cent, respectively, versus vitamin $C$. These intermittent protective treatment regimens also reduced all-cause acute clinic visits, asymptomatic parasitaemia and anaemia. ${ }^{93}$

A stratified, cluster-randomised, double-blind, placebo-controlled trial in 30 primary schools in Kenya involving 2604 children (five to 18 years) who received sulphadoxine-pyrimethamine and 2302 dual placebos. At 12 months, the prevalence of anaemia averaged 6.3 per cent (intermittent protective treatment) and 12.6 per cent (placebo); significant improvement was evident in two measures of cognitive ability. ${ }^{94}$

A randomised trial in children (six months to ten years) in Mali; 262 received either sulphadoxine-pyrimethamine twice with an eight-week interval or no intermittent protective treatment. In treated subjects, the annual incidence rate of clinical malaria was reduced by 42.5 per cent in an area with intense seasonal transmission..$^{95}$

92 Chandramohan, D., Webster, J., Smith, L., Awine, T., Owusu-Agyei, S. \& Carneiro, I. 2007. Is the Expanded Programme on Immunisation the most appropriate delivery system for intermittent preventive treatment of malaria in West Africa? Tropical Medicine \& International Health, 12(6):743-50. [https://doi.org/10.1111/j.1365-3156.2007.01844.x]; Maltha, J., Gillet, P. \& Jacobs, J. 2013. Malaria rapid diagnostic tests in endemic settings. Clinical Microbiology and Infection, 19(5):399-407. [https://doi.org/10.1111/1469-0691.12151].

93 Barger et al., 2009.

94 Clarke, S.E., Jukes, M.C., Njagi, J.K. \& Khasakhala, L., Cundill, B., Otido, J., Crudder, C., Estambale, B.B. \& Brooker, S. 2008. Effect of intermittent preventive treatment of malaria on health and education in schoolchildren: a cluster-randomised, double-blind, placebo-controlled trial. The Lancet, 372(9633):127-138. [https://doi.org/10.1016/S0140-6736(08)61034-X].

95 Dicko, A., Sagara, I., Sissoko, M.S., Guindo, O., Diallo, A.I., Kone, M., Toure, O.B., Sacko, M. \& Doumbo, O.K. 2008. Impact of intermittent preventive treatment with 
A randomised, double-blind, placebo-controlled trial in schoolchildren (six to 14 years) in Uganda; 740 were randomised to dihydroartemisininpiperaquine given once a month, once a school term (four treatments over 12 months), or placebo, and followed for 12 months. Monthly intermittent preventive treatment with dihydroartemisinin-piperaquine offered remarkable protection; reducing the incidence of malaria by 96 per cent, the prevalence of asymptomatic parasitaemia by 94 per cent and the prevalence of anaemia by 40 per cent in schoolchildren living in a high-malaria-transmission setting. ${ }^{96}$

Nankabirwa and colleagues (Wandera, Amuge, Kiwanuka, Dorsey, Rosenthal, Brooker, Staedke and Kamya, 2014b) summarised eight intermittent protective treatment studies from Africa. ${ }^{97}$ Trials data, including a 2011 systematic review and meta-analysis on efficacy and safety of 12 trials (seven controlled, five controlled) generally indicate intermittent protective treatment regimens provide significant benefit for school-age children, achieving reduced rates of infection, improved health, a decrease in absence from school, enhanced academic achievement, and improved cognitive ability. ${ }^{98}$ The consensus is that intermittent protective treatment is a safe, simple strategy offering remarkable protection in schoolchildren

sulphadoxine-pyrimethamine targeting the transmission season on the incidence of clinical malaria in children in Mali. Malaria Journal, 7(123).

[https://doi.org/10.1186/1475-2875-7-123].

96 Nankabirwa, J.I., Wandera, B., Amuge, P., Kiwanuka, N., Dorsey, G., Rosenthal, P.J., Brooker, S.J., Staedke, S.G. \& Kamya, M.R. 2014b. Impact of intermittent preventive treatment with dihydroartemisinin-piperaquine on malaria in Ugandan schoolchildren: a randomized, placebo-controlled trial. Clinical Infectious Diseases, 58(10):1404-1412. [https://doi.org/10.1093/cid/ciu150].

97 Nankabirwa et al., 2014 b.

98 Ibid.;Bundy, D.A.P., Shaeffer, S., Jukes, M., Beegle, K., Gillespie, A., Drake, L., Lee, S.F., Hoffman, A., Jones, J., Mitchell, A., Barcelona, D., Camara, B., Golmar, C., Savioli, L., Sembene, M., Takeuchi, T. \& Wright, Cet al. 2006. School Based Health and Nutrition Programs. In: Breman, J.G., Measham, A.R., Alleyne, G., Jamison, D.T., Claeson, M., Evans, D.B., Jha, P., Mills, A. \& Musgrove, P. (eds). Disease Control Priorities for Developing Countries. Breman JG, Measham AR, Alleyne G et al. (eds). Oxford: Oxford University Press. 2006:1091-1108; Clarke et al., 2004; Clarke et al., 2008; Dicko et al., 2008; Clarke, S.E., Rouhani, S., Diarra, S., Saye, R., Bamadio, M., Jones, R., Traore, E., Traore, K., Jukes, M.C.H., Thuilliez, J., Brooker, S., Roschnik, N. \& Sacko, M. 2017. Impact of a malaria intervention package in schools on Plasmodium infection, anaemia and cognitive function in schoolchildren in Mali: a pragmatic cluster-randomised trial. BMJ Global Health, 2:e000182. [http://doi.org/10.1136/bmjgh-2016-000182]; Wilson, A.L. \& IPTc Taskforce. 2011. A systematic review and meta-analysis of the efficacy and safety of intermittent preventive treatment of malaria in children (IPTc). PLoS One, 6(2):e16976. [https://doi.org/10.1371/journal.pone.0016976]. 
in high-malarial-transmission settings, and also appears to have a substantial protective effect against all-cause mortality. Clarke and colleagues (Brooker, Njagi, Njau, Estambale, Muchiri and Magnussen, 2004) concluded that effective malaria intermittent protective treatment interventions could be a valuable addition to school health programmes. ${ }^{99}$

While the optimal regimen remains unclear, a 2015 systematic review of five studies assessing efficacy concluded: ${ }^{100}$

Sulphadoxine-pyrimethamine may not be a promising regimen in areas where resistance to this drug is high.

Artemisinin combination therapies (dihydroartemisinin-piperaquine, sulphadoxine-pyrimethamine + amodiaquine) provided acceptable protective efficacy against clinical malaria, parasitaemia and anaemia.

\section{Dihydroartemisinin-piperaquine administered monthly demonstrated the} highest protective efficacy.

$\square$ Combining at least two long half-life drugs such as piperaquine plus sulphadoxine-pyrimethamine may be, at present, the most promising option.

However, in a cluster randomised trial, Halliday and colleagues (Okello, Turner, Njagi, Mcharo, Kengo, Allen, Dubeck, Jukes and Brooker, 2014) failed to show benefit from an intermittent screening and treatment programme. Kenyan primary schools were randomly assigned as intervention or control sites, and 5233 children randomly selected by public health workers were screened using rapid diagnostic testing. The 17.5 per cent rapid diagnostic testing-positive (with or without malaria symptoms) were then treated with artemether-lumefantrine. ${ }^{101}$ Follow up at 12 and 24 months showed no impact for the prevalence of anaemia, or on the prevalence of Plasmodium falciparum infection, or scores of classroom attention. The authors concluded that in this setting, as implemented, intermittent screening and

99 Clarke et al., 2017.

100 Matangila, J.R., Mitashi, P., Da Luz, R.A., Lutumba, P.T., Van Geertruyden, J.P. 2015. Efficacy and safety of intermittent preventive treatment for malaria in schoolchildren: a systematic review. Malaria Journal, 14(450). [https://doi.org/10.1186/s12936-015-0988-5].

101 Halliday, K.E., Okello, G., Turner, E.L., Njagi, K., Mcharo, C., Kengo, J., Allen, E., Dubeck, M.M., Jukes, M.C.H., Brooker, S.J. 2014. Impact of intermittent screening and treatment for malaria among school children in Kenya: a cluster randomized trial. PLoS Medicine, January 28. [https://doi.org/10.1371/journal.pmed.1001594];

Halliday et al., 2014. 
treatment is not effective in improving the health or education of school children. Possible reasons given included:

marked geographical heterogeneity in transmission;

the rapid rate of reinfection following artemether-lumefantrine;

variable reliability of rapid diagnostic testing; and

the relative contribution of malaria to anaemia.

In a review examining why this trial failed to show benefit, Von Seidlein emphasised the results cannot be attributed to methodological uncertainty (the trial was conducted in a large sample of schools, to the highest procedural standards, with excellent adherence and follow-up). ${ }^{102}$ The author concluded that children found to be parasitaemic most likely did benefit from early treatment; however, this was not an outcome the investigators measured. Also, that individual beneficial effects probably did not translate to school-wide outcomes because the trial did not involve treatment of all infections, only those of sufficiently high density to be detectable by rapid diagnostic testing. This author's review of alternative approaches and presumptive treatments extends beyond the school-based scope of this chapter but contains excellent science.

Concerns with seasonal malaria chemoprevention are that it does not provide complete protection and is demanding to deliver for both families and healthcare providers. Furthermore, as sulphadoxine-pyrimethamine selects rapid drugresistant parasites, malaria burden may increase in older children where seasonal malaria chemoprevention is implemented. Also, a risk exists of future emergence of resistance to the drugs currently being used for seasonal malaria chemoprevention. ${ }^{103}$ Although intermittent protective treatment with sulphadoxine-pyrimethamine has reduced malaria episodes by 20 to 59 per cent across Africa, the protective efficacy may also be affected by co-existing malnutrition. In 1200 Ghanaian infants who received sulphadoxine-pyrimethamine or placebo at three, nine and 15 months of age the protective efficacies of intermittent protective treatment in malnourished children were roughly half or less of those observed in nonmalnourished children. ${ }^{104}$

102 Von Seidlein, L. 2014. The failure of screening and treating as a malaria elimination strategy. PLoS Med, 11(1):e1001595. [https://doi.org/10.1371/journal.pmed.1001595].

103 Greenwood et al., 2017.

104 Danquah, I., Dietz, E., Zanger, P., Reither, K., Ziniel, P., Bienzle, U. \& Mockenhaupt, F.P. 2009. Reduced efficacy of intermittent preventive treatment of malaria in malnourished children. Antimicrobial Agents and Chemotherapy, 53(5):1753-1759.

[https://doi.org/10.1128/AAC.01723-08]. 


\section{Mass drug administration}

Mass drug administration is a WHO endorsed a strategy to control Neglected Tropical Diseases, a group of 13 major disabling conditions among the most common chronic infections in the world's poorest people; seven of these are now targeted using mass drug administration - ascariasis, trichuriasis, hookworm infection, schistosomiasis, lymphatic filariasis, trachoma, and onchocerciasis. ${ }^{105}$ A key component of current Neglected Tropical Diseases control policy is at least annual preventive chemotherapy distributed through school-based mass drug administration initiatives; hence, these policies offer the opportunity to deliver school-based malaria strategies conjointly. ${ }^{106}$ The positive impact of combining intermittent protective treatment of malaria with mass drug administration to control intestinal soil-transmitted helminths was evaluated in Ghana in a threearm, open-label intervention study using artemether-lumefantrine; measures of anaemia, sustained attention, and recall in the schoolchildren improved. ${ }^{107}$ The potential and safety of teachers' involvement in mass drug administration were confirmed in Malawi when artemether-lumefantrine as an intermittent protective treatment for malaria was combined with school-based mass drug administration for schistosomiasis and helminths using praziquantel and albendazole. ${ }^{108}$ When this same mass drug combination was administered in Zimbabwe to treat children infected with any of the schistosome species and soil-transmitted helminths, those confirmed to also have malaria via thick blood film microscopy were treated using a combination of chloroquine, sulphadoxine and pyrimethamine according to local case management guidelines. ${ }^{109}$

105 Hotez, P.J., Molyneux, D.H., Fenwick, A., Kumaresan, J., Sachs, S.E., Sachs, J.D. \& Savioli, L. 2007. Control of neglected tropical diseases. The New England Journal of Medicine, 357(10):1018-27. [https://doi.org/10.1056/NEJMra064142].

106 Cohee et al., 2018; WHO. 2013. Schistosomiasis: Progress Report 2001-2011, Strategic Plan 2012-2020. [https://bit.ly/3kkUnJS].

107 Opoku et al., 2016.

108 Cohee et al., 2018.

109 Midzi, N., Mtapuri-Zinyowera, S., Sangweme, D., Paul, N.H., Makware, G., Mapingure, M.P., Brouwer, K.C., Mudzori, J., Hlerema, G., Chadukura, V., Mutapi, F., Kumar, N. \& Mduluza, T. 2011. Efficacy of integrated school based de-worming and prompt malaria treatment on helminths-Plasmodium falciparum co-infections: A 33 months follow up study. BMC International Health and Human Rights, 11(1):9. [https:// doi.org/10.1186/1472-698X-11-9]; Mphwatiwa, T., Witek-McManus, S., Mtali, A., Okello, G., Nguluwe, P., Chatsika, H., Roschnik, N., Halliday, K.E., Brooker, S.J. \& Mathanga, D.P. 2017. School-based diagnosis and treatment of malaria by teachers using rapid diagnostic tests and artemisinin-based combination therapy: experiences and perceptions of users and implementers of the Learner Treatment Kit, southern Malawi. Malaria Journal, 16(318). [https://doi.org/10.1186/s12936-017-1964-z]; Anaba, M.K., 
The addition of antimalarials to these routine annual mass drug administration programmes to control Neglected Tropical Diseases was well-tolerated, safe, beneficial and well-received by parents, and is logical as current national malaria control interventions do not specifically target school-age children, despite evidence that they bear the highest burden of infection. ${ }^{110}$ Hence, combining intermittent protective treatment with mass drug administration strategies is an appealing model; adding malaria treatment to already established platforms for Neglected Tropical Diseases control may also increase the cost-effectiveness of both interventions, leading to increased sustainability.

\section{Rapid diagnostic testing and Artemisinin combination therapy}

A major advantage of rapid diagnostic testing kits is that they provide point-of-care diagnosis, which in turn makes immediate treatment feasible. Rapid diagnostic testing is especially useful where health facilities are scarce and/or operate using staff with minimal skill levels, and when introduced, were quickly shown to be more cost-effective than diagnostic microscopy. ${ }^{111}$ Overall, research confirms that "RDTs represent a cheap diagnostic approach in school malariometric surveys, and can be used to estimate infection prevalence at low and high prevalence categories reliably". ${ }^{112}$

The sensitivity and specificity of rapid diagnostic tests are good enough for them to replace conventional testing for malaria. ${ }^{113}$ However, their usefulness is linked to the accuracy of the diagnoses they provide; while simple to use and the principles of how they work are similar, rapid diagnostic testing kits do vary, and accuracy is user-dependent. Maltha, Gillet and Jacobs (2013) reviewed design limitations and

Ibisomi, L., Owusu-Agyei, S., Chirwa, T., Ramaswamy, R. 2019. Determinants of health workers intention to use malaria rapid diagnostic test in Kintampo North Municipality, Ghana-a cross-sectional study. BMC Health Services Research, 19(1):491.

[https://doi.org/10.1186\%2Fs12913-019-4324-6].

110 Clarke et al., 2008.

111 Wongsrichanalai, C., Barcus, M.J., Muth, S., Sutamihardja, A., Wernsdorfer, W.H. 2007. A review of malaria diagnostic tools: microscopy and rapid diagnostic test (RDT). The American Journal of Tropical Medicine and Hygiene, 77(Supplement 6):119-127. [https://doi.org/10.4269/ajtmh.2007.77.119]; FIND, TDR \& WHO. 2009. Malaria rapid diagnostic test performance. Results of WHO product testing of malaria RDTs: Round. [https://bit.ly/36sOntE].

112 WHO, 2015.

113 Abba, K., Deeks, J.J., Olliaro, P.L., Naing, C.M., Jackson, S.M., Takwoingi, Y., Donegan, S. \& Garner, P. 2011. Rapid diagnostic tests for diagnosing uncomplicated P. falciparum malaria in endemic countries. Cochrane Systematic Review, (7): CD008122. [https://doi.org/10.1002/14651858.CD008122.pub2]. 
end-user errors. ${ }^{114}$ In the context of employing school-based diagnosis, minimising mistakes is crucial; it has been shown that job aids (step-by-step instructions) that supplement manufacturer's instructions can improve performance. ${ }^{15}$

While the positive impact of rapid diagnostic testing on malaria management has been widely demonstrated, field trials have indicated that adherence to test results is sometimes poor, especially in public health settings. However, appropriate training and protocol design improve adherence. ${ }^{116}$ Importantly data from Senegal indicate high adherence to rapid diagnostic testing results in anti-malarial prescribing practice following a national programme to introduce rapid diagnostic testing into public health facilities. Parasite-based diagnosis increased nationally from 3.9 per cent of reported malaria-like febrile illness to 86 per cent over a three-year period, which was also associated with a large reduction in artemisinin combination therapy consumption, demonstrating that effective roll-out and use of malaria rapid diagnostic testing is achievable on a national scale through well planned and structured implementation. ${ }^{117}$ This is relevant to the up-scale of programmes for rapid diagnostic testing use by appropriately trained teachers in schools. The potential for up-scaling was identified in studies that showed:

kits can be stocked and used appropriately outside formal health facilities; and

114 Afenyadu et al., 2005; Maltha, Gillet \& Jacobs, 2013.

115 Rennie, W., Phetsouvanh, R., Lupisan, S., Vanisaveth, V., Hongvanthong, B., Phompida, S., Alday, P., Fulache, M., Lumagui, R., Jorgensen, P., Bell, D. \& Harvey, S. 2007. Minimising human error in malaria rapid diagnosis: clarity of written instructions and health worker performance. Transactions of The Royal Society of Tropical Medicine and Hygiene, 101(1):9-18. [https://doi.org/10.1016/j.trstmh.2006.03.011].

116 Manyando, C., Njunju, E.M., Chileshe, J., Siziya, S., Shiff, C. 2014. Rapid diagnostic tests for malaria and health workers' adherence to test results at health facilities in Zambia. Malaria Journal, 13(166). [https://doi.org/10.1186/1475-2875-13-166]; Burchett, H.E., Leurent, B., Baiden, F., Baltzell, K., Björkman, A., Bruxvoort, K., Clarke, S., DiLiberto, D., Elfving, K., Goodman, C., Hopkins, H., Lal, S., Liverani, M., Magnussen, P., Mårtensson, A., Mbacham, W., Mbonye, A., Onwujekwe, O., Roth Allen, D., Shakely, D., Staedke, S., Vestergaard, L.S., Whitty, C., Wiseman, V. \& Chandler, C.I. 2017. Improving prescribing practices with rapid diagnostic tests (RDTs): synthesis of 10 studies to explore reasons for variation in malaria RDT uptake and adherence. BMJ Open, 7(3): e012973. [https://doi.org/10.1136/bmjopen-2016-012973].

117 Thiam, S., Thior, M., Faye, B., Ndiop, M., Diouf, M.L., Diouf, M.B., Diallo, I., Fall, F.B., Ndiaye, J.L., Albertini, A.., Lee, E., Jorgensen, P., Gaye, O. \& Bell, D. 2011. Major reduction in anti-malarial drug consumption in Senegal after nation-wide introduction of malaria rapid diagnostic tests. PLoS One. 6(4):e18419. [https://doi. org/10.1371\%2Fjournal.pone.0018419]. 
basic training programmes enable teachers and other individuals without a formal health care background to use rapid diagnostic testing reliably and effectively. ${ }^{118}$

Artemisinin combination therapy is the first-line treatment for Plasmodium falciparum malaria recommended since 2001 by the WHO for use worldwide in all countries with endemic disease. ${ }^{119}$ Artemisinin combination therapies are partly gametocytocidal, so widespread deployment can be expected to affect the transmission of malaria in communities where a high proportion of infected individuals have symptoms and seek treatment. ${ }^{120}$ Benefits of genuine artemisinin combination therapies include high efficiency, fast action, few adverse effects, low cost and the potential to lower the rate at which resistance emerges and spreads. ${ }^{121}$ Care must be taken in low- and middle-income countries over the choice of the preparation used as sub-standard and counterfeit products with little or no

118 Kyaabayinze, D.L., Asiimwe, C., Nakanjko, D., Nabakooza, J., Counihan, H., Tibenderana, J.K. 2010. Use of RDTs to improve malaria diagnosis and fever case management at primary health care facilities in Uganda. Malaria Journal, 9(200). [https://doi.org/10.1186/1475-2875-9-200]; Macnab et al., 2016a \& 2016b; Mbonye, A.K., Magnussen, P., Lai, S., Hansen, K.S., Cundill, B., Chandler, C. \& Clarke, S.E. A cluster randomized trial introducing rapid diagnostic tests in registered drug shops in Uganda: Impact on appropriate treatment of malaria. PLoS One, 10(7):e0129545. [https://doi.org/10.1371/journal.pone.0129545]; Visser et al., 2017; Halliday et al., 2014; Kyaabayinze et al., 2010; Counihan, H., Harvey, S.A., Sekeseke-Chinyama, M., Hamainza, B., Banda, R., Malambo, T., Masaninga, F. $\&$ Bell, D. 2012. Community health workers use malaria rapid diagnostic tests (RDTs) safely and accurately: results of a longitudinal study in Zambia. The American Journal of Tropical Medicine and Hygiene, 87(1):57-63. [https://doi.org/10.4269/ ajtmh.2012.11-0800]; Witek-McManus, S., Mathanga, D.P., Verney, A., Mtali, A., Ali, D., Sande, J., Mwenda,R., Ndau, S., Mazinga, C., Phondiwa, E., Chimuna, T., Melody, D., Roschnik, N., Brooker, S.J. \& Halliday, K.E. 2015. Design, implementation and evaluation of a training programme for schoolteachers in the use of malaria rapid diagnostic tests as part of a basic first aid kit in southern Malawi. BMC Public Health, 15(1):904. [https://doi.org/10.1186/s12889-015-2228-x].

119 WHO, 2019; Adjuik, M., Babiker, A., Garner, P., Olliaro, P., Taylor, W., White, N. \& International Artemisinin Study Group. 2004. Artesenuate combinations for treatment of malaria: meta-analysis. The Lancet, 363(9402):9-17. [https://doi.org/10.1016/s01406736(03)15162-8]; Benjamin, J., Moore, B., Lee, S., Senn, M., Griffin, S., Lautu, D., Salman, S., Siba, P., Mueller, I. \& Davis, T. 2012. Artemisinin-naphthoquine combination therapy for uncomplicated pediatric malaria: a tolerability, safety, and preliminary efficacy study. Antimicrobial Agents and Chemotherapy, 56(5):2465-2471.

[https://doi.org/10.1128/AAC.06248-1].

120 O’Meara et al., 2010.

121 WHO, 1992; Adjuik et al., 2004. 
efficacy are unfortunately widespread, and continue to pose severe threats to human health. Estimates indicate that in 2013 more than 100000 deaths in subSaharan Africa in children under five years of age were associated with poor quality antimalarials. ${ }^{122}$ In addition to risking the health of the patient because of limited or absent efficacy, falsified medicines also contribute significantly to the risk of drug resistance developing. It is also important to note recent concerns that the efficacy of artemisinin combination therapy has declined on the Thai-Cambodian border (a site of historically emerging antimalarial-drug resistance); resistance is characterised by slow parasite clearance in vivo without corresponding reductions on conventional in vitro susceptibility testing. ${ }^{123}$

Since the efficacy of artemisinin combination therapies is high, more could be achieved if their potential was optimised through effective coverage and increased availability; the major challenge is finding effective ways to deliver these drugs to those who need them most. ${ }^{124}$ Evaluation of a community case management approach, where a variety of trained providers delivered artemisinin combination therapy to children in five African cities, found this model feasible and acceptable, but that innovation was required to overcome the struggle of competing against sources using established healthcare providers. ${ }^{125}$ Other exploratory avenues included deployment through trained agents in drug stores, pharmacies and private medical clinics, and teachers in school programmes. ${ }^{126}$

122 Brooker et al., 2008.

123 Dondorp, A.M., Nosten, F., Yi, P., Das, D., Phyo, A.P., Tarning, J., Lwin, K.M., Ariey, F., Hanpithakpong, W., Lee, S.J., Ringwald, P., Silamut, K., Imwong, M., Chotivanich, K., Lim, P., Herdman, T., An, S.S., Yeung, S., Singhasivanon, P., Day, N., Lindegardh, N., Socheat, D. \& White, N.J. 2009. Artemisinin Resistance in Plasmodium Falciparum Malaria. The New England Journal of Medicine, 361(5):455-467. [https://doi.org/10.1056/ NEJMoa0808859].

124 Mutabingwa, 2005; Whitty, C.J.M., Chandler, C., Ansah, E., Leslie, T., Staedke, S.G. 2008. Deployment of ACT antimalarials for treatment of malaria: challenges and opportunities. Malaria Journal, 7(S7). [https://doi.org/10.1186/1475-2875-7-S1-S7].

125 Akweongo, P., Agyei-Baffour, P., Sudhakar, M., Simwaka, B.N., Konaté, A.T., Adongo, P.B., Browne, E.N., Tegegn, A., Ali, D., Traoré, A., Amuyunzu-Nyamongo, M., Pagnoni, F. \& Barnish, G. 2011. Feasibility and acceptability of ACT for the community case management of malaria in urban settings in five African sites. Malaria Journal, 10(240). [https://doi.org/10.1186/1475-2875-10-240].

126 Macnab et al., 2016a; Mbonye et al., 2015; Halliday et al., 2014; President's Malaria Initiative (PMI). 2006. Uganda: Malaria Country Action Plan, February. [https://bit.ly/3aPCYWy] (Accessed 6 December 2019). 


\section{Developing a model for teacher-driven school-based care}

If teachers could be trained to promptly detect and adequately treat uncomplicated malaria promptly, and promptly refer severe forms of the disease, improved access to this critical service would be achieved. For example, school absenteeism and man-hours lost to the disease would be reduced, especially in these rural communities. ${ }^{127}$

These words were written in 2005 in a review on how to improve access to early treatment. ${ }^{128}$ Afenyadu, Agyepong, Barnish and Adjei (2005)'s concept that teachers should be trained to intervene presaged the calls for innovative solutions to the health burden of malaria in school-children from the WHO, and other experts. ${ }^{129}$ The authors also identified that decentralisation to the district level, and collaboration between the health and education sectors were required to improve the health status of school children in rural communities.

In an early exploratory trial, 12 Ghanaian schools trained teachers to diagnose and treat uncomplicated malaria and recognise and refer severe forms of the disease for appropriate treatment. The five-day training included:

Instruction in diagnosis using an adaptation of the WHO diagnostic algorithm designed for training Community Health Workers; ${ }^{130}$ and

Chemotherapy with chloroquine (the drug of choice at the time).

Of the fevers diagnosed as presumptive malaria by teachers, 93 per cent met the case definition. The proportion adequately treated initially (75 per cent) was improved by pre-packaging the antimalarials to simplify correct dosing. The authors concluded that primary school teachers in rural communities are willing partners in bringing early case detection and adequate management closer to the people. ${ }^{131}$

Findings were similar in a contemporaneous study in Tanzania where the clinical diagnostic algorithm included measurement of body temperature, although training in diagnosis and treatment only involved headteachers and selected 'health' teachers. ${ }^{132}$ Treatment outcome was measured using a thick blood smear examination rather than prescriber compliance.

127 Afenyadu et al., 2005.

128 Ibid.

129 WHO, 2008; Sachs \& Malaney, 2002; Agyepong et al., 2017; Temperley et al., 2008;

Houngbedji et al., 2015; Khatib et al., 2013.

130 WHO, 1992.

131 Afenyadu et al., 2005.

132 Magnussen, P., Ndawi, B., Sheshe, A.K., Byskov, J. \& Mbwana, K. 2001. Malaria 
In Malawi, teachers were taught to use pupil-treatment kits containing sulphadoxine-pyrimethamine tablets dispensed according to national guidelines. The authors concluded school-based interventions could play a part in mitigating malaria based on comparison of overall and malaria-specific mortality rates; these were calculated for the three years before and two years after the intervention, with rates dropping from 2.2 to 1.44 deaths $/ 1000$ student-years, and 1.28 to 0.44 deaths/ 1000 student-years respectively. ${ }^{133}$

In a second Malawian school-based programme, teachers were trained to identify and treat children suffering from malaria. Intervention and comparison schools were matched; retrospective evaluation used school administrative records. Significant reductions in general absenteeism and grade repetition by students were noted. ${ }^{134}$

The first model combining teacher-administered rapid diagnostic testing with artemisinin combination therapy was developed as a community-outreach healtheducation project by a local non-governmental organisation after teachers had identified the unacceptable health burden malaria was creating among their pupils. ${ }^{135}$ The decision to introduce school-based rapid diagnostic testing/artemisinin combination therapy was made collaboratively during community-based dialogue. Up to that time all pupils sick at school were sent home devolving care to parents, however many of those presumed to have malaria never received timely diagnosis and treatment, so morbidity and the duration of absence from school were high.

Macnab and colleagues (Mukisa, Mutabazi \& Steed, 2016a; Mutabazi, Mukisa, Eliab, Kigozi \& Steed, 2016b) evaluated this two-year intervention trialling teacherdriven rapid diagnostic testing/artemisinin combination therapy in 2016; four rural schools in Uganda were involved. ${ }^{136}$ All teachers were trained broadly on malaria causation, prevention and treatment; two volunteer teachers in each school were specifically trained to collect the required data, conduct rapid diagnostic testing in

diagnosis and treatment administered by teachers in primary schools in Tanzania.

Tropical Medicine \& International Health, 6(4):273-79. [https://doi.org/10.1046/j.13653156.2001.00720.x].

133 Pasha, O., Del Rosso, J., Mukaka, M. \& Marsh, D. The effect of providing fansidar (sulfadoxine-pyrimethamine) in schools on mortality in school-age children in Malawi. The Lancet, 361(9357):577-578. [https://doi.org/10.1016/s0140-6736(03)12511-1].

134 Simwaka, B.N., Simwaka, K. \& Bello, G. 2009. Retrospective analysis of a school-based malaria treatment programme demonstrates a positive impact on health and education outcomes in Mangochi district. Malaria Journal, 1(4):492-506.

[https://doi.org/10.1080/19439340903342336].

135 Macnab et al., 2016a.

136 Ibid.; Macnab et al., 2016b. 
children falling sick at school and administer artemisinin combination therapy to those testing positive. The effect on absenteeism was evaluated as a surrogate for morbidity. A year of baseline pre-intervention data was compared to the subsequent year when all sick children had a teacher-administered rapid diagnostic testing and prompt artemisinin combination therapy if they tested positive. A single dose artemisinin combination therapy preparation was used to ensure a full course of treatment was completed, and eliminate any partial treatment bias.

Pre-intervention 953/1 764 pupils were sent home due to presumed infectious illness; parental management only approached the WHO standards for malaria diagnosis and treatment in 1:4 children, and the mean duration of absence from school was 6.5 school days. During school-based teacher-administered rapid diagnostic testing/artemisinin combination therapy, 1 066/1 774 pupils were identified as sick, 765/1 066 were rapid diagnostic test positive and received artemisinin combination therapy, and duration of absence fell to 0.6 days. (Table 14.1). After being promptly treated, many children felt well enough to ask to return to class within hours, and consequently had no days when they were absent from school.

Overall, absence from school was reduced by 60.8 per cent during this intervention. If the same percentage of children sent home in year one had malaria as were diagnosed using rapid diagnostic testing in year two, this would equate to 1358 cases in 1775 children over the two years - a malaria incidence rate of 79 per cent across the four schools. No children died from malaria during the intervention year. Delivery was readily implemented and sustained; teachers participated willingly. 
Table 14.1 Composite data from the school-based teacher-driven rapid diagnostic testing (RDT) or artemisinin combination therapy (ACT) malaria intervention programme in four Ugandan schools, comparing a pre-intervention year with a year of project intervention followed by three years of independent school-sustained delivery.

\begin{tabular}{|c|c|c|c|c|c|}
\hline & $\begin{array}{l}\text { Year } 1 \\
\text { Pre-intervention } \\
\text { Baseline }\end{array}$ & $\begin{array}{l}\text { Year } 2 \\
\text { Intervention }\end{array}$ & $\begin{array}{l}\text { Year } 3 \\
\text { Independent } \\
\text { conduct } \\
\text { year } 1\end{array}$ & $\begin{array}{l}\text { Year } 4 \\
\text { Independent } \\
\text { conduct } \\
\text { year } 2\end{array}$ & $\begin{array}{l}\text { Year } 5 \\
\text { Independent } \\
\text { conduct } \\
\text { year } 3\end{array}$ \\
\hline $\begin{array}{l}\text { Children } \\
\text { Age years }\end{array}$ & $\begin{array}{l}1764 \\
5-13\end{array}$ & $\begin{array}{l}1774 \\
5-13\end{array}$ & $\begin{array}{l}1798 \\
5-14\end{array}$ & $\begin{array}{l}1797 \\
5-14\end{array}$ & $\begin{array}{l}1791 \\
5-14\end{array}$ \\
\hline $\begin{array}{l}\text { Sick at } \\
\text { school } \\
\text { Total }\end{array}$ & $\begin{array}{l}\text { Sent home } \\
539\end{array}$ & $\begin{array}{l}\text { Teacher } \\
\text { assessed } \\
1066\end{array}$ & $\begin{array}{l}\text { Teacher } \\
\text { assessed } \\
957\end{array}$ & $\begin{array}{l}\text { Teacher } \\
\text { assessed } \\
1317\end{array}$ & $\begin{array}{l}\text { Teacher } \\
\text { assessed } \\
632\end{array}$ \\
\hline $\begin{array}{l}\text { RDT + ve } \\
\text { Rx ACT }\end{array}$ & & $\begin{array}{l}715(68 \%) \\
715\end{array}$ & $\begin{array}{l}597(62 \%) \\
597\end{array}$ & $\begin{array}{l}819(62 \%) \\
819\end{array}$ & $\begin{array}{l}819(62 \%) \\
819\end{array}$ \\
\hline $\begin{array}{l}\text { Absence } \\
\text { School days } \\
\text { mean (SD) }\end{array}$ & All illnesses & Malaria & Malaria & Malaria & Malaria \\
\hline $\begin{array}{l}\quad(p= \\
\text { significance } \\
\text { compared } \\
\text { to pre- } \\
\text { intervention } \\
\text { Year 1) }\end{array}$ & $6.5(3.17)$ & $\begin{array}{l}0.59(0.64) \\
p=<0.001\end{array}$ & $\begin{array}{l}0.49(0.38) \\
p=<0.001\end{array}$ & $\begin{array}{l}0.37(0.35) \\
p=<0.001\end{array}$ & $\begin{array}{l}0.59(0.64) \\
p=<0.001\end{array}$ \\
\hline $\begin{array}{l}\text { Project } \\
\text { action }\end{array}$ & $\begin{array}{l}\text { Baseline data } \\
\text { Teacher Training } \\
\text { re. RDT/ACT }\end{array}$ & Project data & $\begin{array}{l}\text { f/up data } \\
\text { Refresher } \\
\text { training }\end{array}$ & f/up data & $\begin{array}{l}\text { f/up data } \\
\text { Refresher } \\
\text { training }\end{array}$ \\
\hline Oversight & Monthly visits & Weekly visits & Site visit/term & Site visit/term & Site visit/term \\
\hline
\end{tabular}

In 2017, Mphwatiwa and colleagues (Witek-McManus, Mtali, Okello, Nguluwe, Chatsika, Roschnik, Halliday, Brooker and Mathanga) reported on a similar approach in Malawi. The experiences and perceptions of users and implementers from 6/29 primary schools, where teachers were trained to test and treat were evaluated from eight focus groups and 20 in-depth interviews.

Findings included:

\section{$\square$ Positive outcomes}

Trained teachers were trusted providers of malaria testing and treatment; access to treatment by children increased; absenteeism decreased. 


\section{Potential barriers}

Increased teacher workloads and the need for supervision from health workers are potential barriers.

\section{Concerns}

Lack of incentives and concerns for the sustainability of drug supply; an impressive element was that this trial was established following intersectoral collaboration between the Ministry of Health and Ministry of Education Science and Technology. ${ }^{137}$

Both Macnab et al. and Mphwatiwa et al. concluded that training teachers to 'test and treat' was well-received, supported national health and education policies and was seen to be a worthwhile intervention. ${ }^{138}$ Importantly, sustainability is demonstrated by ongoing data from Uganda shown in Table 14.1. For three years post-intervention the target schools have independently continued rapid diagnostic testing and artemisinin combination therapy, and the significant reduction in malaria morbidity (reduction in absenteeism) was sustained; there is also robust evidence of greater knowledge about many aspects of malaria among the schoolchildren and in the broader community. ${ }^{139}$ Even during restricted schooling necessitated by the Covid-19 pandemic, teachers were motivated to continue to offer scaled back diagnostic and treatment services; these were modified to comply with infection control measures to limit spread of Covid-19.

\section{Training}

Schools present an obvious opportunity to improve the access of children to health services; a key question in the context of malaria is can teachers be trained to provide appropriate diagnostic and treatment services for school children.

Witek-McManus and colleagues (Mathanga, Verney, Mtali, Ali, Sande, Mwenda, Ndau, Mazinga, Phondiwa, Chimuna, Melody, Roschnik, Brooker and Halliday, 2015) evaluated the training and performance of teachers in Malawi. Training materials were first piloted in a four-day workshop; assessment data informed the design of the definitive seven-day training. Fifteen teachers were evaluated at four stages: pilot training, two weeks post-pilot, following final training and seven months later. Conclusions were that appropriately trained teachers could use rapid diagnostic testing and artemisinin combination therapy competently to test and

137 Mphwatiwa et al., 2017.

138 Macnab et al., 2016b; Mphwatiwa et al., 2017.

139 Macnab et al., 2016a. 
treat children at school for uncomplicated malaria. They do so safely and accurately, demonstrating a comparable skill level to other non-health professional users of rapid diagnostic testing. ${ }^{140}$ Teacher training in Uganda was via a one-day workshop; two trained laboratory staff and two nurses included instruction on:

evaluation of a child for a presumed infectious illness;

theory and practice for the conduct of rapid diagnostic testing and administration of artemisinin combination therapy;

record-keeping; and

needle safety and waste disposal techniques. ${ }^{141}$

Practical competencies were re-evaluated during project implementation, and at a refresher course given two years later. Importantly, in both projects, all teachers correctly performed safe blood collection and handling, accurate interpretation of rapid diagnostic testing, correctly dispensed artemisinin combination therapy and sustained this competency for the duration of the evaluation. ${ }^{142}$

All evaluative literature stresses that effective training and comprehensive instructions on rapid diagnostic testing and artemisinin combination therapy are essential. ${ }^{143}$ Learning points from training for personnel other than teachers warrant inclusion, including the systematic review of six published and six unpublished studies by Visser and colleagues (Bruxvoort, Maloney, Leslie, Barat, Allan, Ansah, Anyanti, Boulton, Clarke, Cohen, Cohen, Cutherell, Dolkart, Eves, Fink, Goodman, Hutchinson, Lal, Mbonye, Onwujekwe, Petty, Pontarollo, Poyer, Schellenberg, Streat, Ward, Wiseman, Whitty, Yeung, Cunningham and Chandler, 2017). Factors deemed to have a positive effect on rapid diagnostic testing uptake and provider adherence to test results included the length of provider training and adequacy of support or supervision. Common challenges were the disposal of medical waste and referral of complicated patients to public facilities. ${ }^{144} \mathrm{~A}$ problem

140 Witek-McManus et al., 2015.

141 Macnab et al., 2016b.

142 Ibid.; Witek-McManus et al., 2015.

143 Visser et al., 2017; Burchett, H.E., Leurent, B., Baiden, F., Baltzell, K., Björkman, A., Bruxvoort, K., Clarke, S., DiLiberto, D., Elfving, K., Goodman, C., Hopkins, H., Lal, S., Liverani, M., Magnussen, P., Mårtensson, A., Mbacham, W., Mbonye, A., Onwujekwe, O., Roth Allen, D., Shakely, D., 2017. Improving prescribing practices with rapid diagnostic tests (RDTs): synthesis of 10 studies to explore reasons for variation in malaria RDT uptake and adherence. BMJ Open, 7(3):e012973. [https://doi.org/10.1136/ bmjopen-2016-012973].

144 Visser et al., 2017. 
of retained preference for clinical diagnosis was often seen to persist in public health workers; this will not compromise teacher performance as they will only gain experience with the rapid diagnostic testing diagnostic pathway. ${ }^{145}$

Training approaches need to emphasise how to minimise common errors, and periodic performance appraisals to monitor user behaviour should be a basic component of rapid diagnostic testing implementation. ${ }^{146}$ Learning points on how errors are made and practical ways to avoid them are necessary as even simple diagnostic tests can be poorly performed and interpreted; examples include ensuring the correct volume of buffer is added to the test cassette, and the appropriate wait time elapses before reading the result. ${ }^{147}$ Trainers must be flexible and responsive to learner's priorities, expectations and capacities, and trainee providers learn from being involved in the exploratory community dialogue necessary before programme implementation. ${ }^{148}$ A proper understanding of the aims and expected benefits of testing, opportunities to learn from experienced staff, and exposure to 'champions' for the intervention, were three training fundamentals identified as lacking where the use of rapid diagnostic testing by trained health workers remained low. ${ }^{149}$

\section{Cost}

The cost and cost-benefit of any school-based health intervention, including rapid diagnostic testing/artemisinin combination therapy, are relevant to their deployment. Rapid diagnostic testing has the potential to be cost-effective in most parts of sub-Saharan Africa; the cost of artemisinin combination therapies is a potential barrier to scale-up of initiatives that use them, ${ }^{150}$ but substantial costbenefit will accrue from improving the health of school-aged children in ways that

145 Manyando et al., 2014; Burchett et al., 2017.

146 Rennie et al., 2007.

147 Ibid.; Counihan et al., 2012.

148 Witek-McManus et al., 2015; Burchett et al., 2017; Macnab et al., 2016b; Mbonye et al., 2015; Macnab, Stewart \& Gagnon, 2014; Macnab, 2013.

149 Manyando et al., 2014; Anaba et al., 2019; Onwujekwe, O., Mangham-Jefferies, L., Cundill, B., Alexander, N., Langham, J., Ibe, O., Uzochukwu, B. \& Wiseman, V. 2015. Effectiveness of provider and community interventions to improve treatment of uncomplicated malaria in Nigeria: a cluster randomized controlled trial. PLoS One, 10(8):e0133832. [https://doi.org/10.1371/journal.pone.0133832].

150 Shillcutt, S., Morel, C., Goodman, C., Coleman, P., Bell, D., Whitty, C.J. \& Mills, A. 2008. Cost-effectiveness of malaria diagnostic methods in sub-Saharan Africa in an era of combination therapy. Bulletin of the WHO, 86(2):101-10. [https://doi.org/10.2471/blt.07.042259]; Mutabingwa, 2005. 
aid cognitive development and promote educational achievement; future research is needed to establish cost benefits accrued in this way.

In 2000, programmes to provide diagnosis and treatment in schools were deemed an affordable approach after cost analysis of options in Kenyan schools concluded that delivery of chemoprophylaxis would be prohibitively expensive; school health models where teachers implement programmes providing deworming and micronutrients had already shown reduced delivery costs. ${ }^{151}$

In 2008, studies comparing presumptive treatment and rapid diagnostic testing use in rural health facilities in sub-Saharan Africa deemed the intervention costeffective, if it proved less costly and more effective, or an incremental cost per disability-adjusted life year of less than 150 US dollars was averted. ${ }^{152}$ In the same year, cost of teacher-delivered intermittent protective treatment in Kenya was estimated to be 1.88 US dollars per child treated per year. The largest components were drug and teacher training costs. Set-up accounted for 13.2 per cent of overall costs (equivalent to 0.25 US dollars per child) and recurrent costs 86.8 per cent (1.63 US dollars per child per year). Cost-benefit analysis equated each anaemia case averted to 29.84 US dollars and each Plasmodium falciparum parasitaemia case averted to 5.36 US dollars. ${ }^{153}$

In 2009 benefits far outweighed costs where teachers were trained to identify and treat children with malaria in Malawi; cost-benefit accrued from significant reductions in both general absenteeism and grade repetition by students. ${ }^{154}$

In 2011 the estimated cost of school-based intermittent screening and treatment, again from Kenya, was 6.61 US dollars per child screened. Key components were salaries 36 per cent and rapid diagnostic testing kits 22 per cent, and almost half the intervention cost (47 per cent) comprised redeployment of existing resources, including health worker time and use of hospital vehicles. The authors estimated that costs would likely reduce by 40 per cent with changes in delivery, including the use of alternative rapid diagnostic testing kits and removal of supervised treatment. ${ }^{155}$

151 Brooker et al., 2000; Clarke et al., 2004; Brooker et al., 2008; Fernando, S.D.,

Rodrigo, C. \& Rajapaske, S. 2010. The 'hidden' burden of malaria: cognitive impairment following infection. Malaria Journal, 9(366). [https://doi.org/10.1186/1475-2875-9-366].

152 Shillcutt et al., 2008.

153 Temperley et al., 2008.

154 Simwaka, Simwaka \& Bello,2009.

155 Drake et al., 2011. 
In 2016 the reported cost for school-based rapid diagnostic testing kits and artemisinin combination therapy supplies in Uganda was 0.50 and 2.20 US dollars, respectively. For every three sick/febrile children tested, two were rapid diagnostic testing positive. Cost savings were subsequently made when the single dose artemisinin combination therapy formulation used to eliminate any partial treatment bias was replaced with a conventional three-day six dose preparation costing one US dollar. Training and supervision costs were not included as the programme was delivered as part of aid provided by a medical charity. ${ }^{156}$

Affordability and cost-effectiveness are important determinants of the longterm sustainability of school-based treatment; here, a key issue will be drug choice. Drugs best suited to mass treatment programmes should be cheap, easy to administer, preferably as a single dose, and well-tolerated with minimal sideeffects; for intermittent protective treatment, a long half-life is also advantageous. ${ }^{157}$ A global artemisinin combination therapy subsidy would significantly increase usage of artemisinin combination therapies and reduce retail price; in rural Tanzania, a 90 per cent subsidy increased the proportion of consumers purchasing artemisinin combination therapies from one per cent to 44.2 per cent one year later, and purchasing for children rose considerably. ${ }^{158}$

Importantly, effective programme rollout offers potential overall savings. In Senegal, a major reduction in anti-malarial drug consumption occurred after nation-wide introduction of rapid diagnostic testing, and considerable cost-savings were achieved through centralised artemisinin combination therapy procurement; half of the global demand for antimalarials has been estimated to be due to overuse in patients without malaria. ${ }^{159}$

156 Macnab et al., 2016a.

157 Temperley et al., 2008.

158 Sabot, O.J., Mwita, A., Cohen, J.M., Ipuge, Y., Gordon, M., Bishop, D., Odhiambo, M., Ward, L. \& Goodman, C. 2011. Piloting the global subsidy: the impact of subsidized artemisinin-based combination therapies distributed through private drug shops in rural Tanzania. PLoS One. 4(9):e6857. [https://doi.org/10.1371/journal.pone.0006857].

159 Thiam et al., 2011; Cohen, J.M., Woolsey, A.M., Sabot, O.J., Gething, P.W., Tatem, A.J. \& Moonen, B. 2012. Optimizing investments in malaria treatment and diagnosis. Science, 338(6107):612-614. [https://doi.org/10.1126/science.1229045]. 


\section{Future directions}

In Africa, there is increasing evidence of the dramatic reductions in malaria mortality and morbidity in early childhood due to recent up-scaling of malaria control efforts. ${ }^{160}$

Coincident with this epidemiologic change reported in 2008 by Temperley and colleagues (Mueller, Njagi, Akhwale, Clarke, Jukes, Estambale and Brooker), there was increased recognition of the consequences of malaria in children of schoolage, including the detrimental effects on haemoglobin levels, and on learning and educational achievement. As a result, interest grew about the control of malaria in older children who attend school and calls followed for innovative concepts as to how this could be achieved. ${ }^{161}$ In response, models were developed that provide school-children with access to accurate diagnosis and treatment in endemic areas, reduce morbidity, and increase the capacity of children to benefit from their education. We now have evidence from many useful trials of 'what works and why' to guide future directions.

What school-based malaria testing and treatment is undertaken in future will depend on priorities set nationally, which in turn require vision beyond the conventional political time frame, but the benefits that are there to be achieved for school-children at risk for malaria are now explicit. While funding agencies tend to call for bold, novel and disruptive thinking, there are strong grounds to argue that substantive investment in proven school-based models is needed in parallel.

160 Temperley et al., 2008.

161 Ibid. Kurtzhals, J.A., Addae, M.M., Akanmori, B.D., Dunyo, S., Koram, K.A., Appawu, M.A., Nkrumah, F.K. \& Hviid, L. 1999. Anaemia caused by asymptomatic Plasmodium falciparum infection in semi-immune African school children.

Transactions of The Royal Society of Tropical Medicine and Hygiene, 93(6):623-627. [https://doi.org/10.1016/s0035-9203(99)90073-1]; Koukounari, A., Estambale, B.B.A., Njagi, J.K., Cundill, B., Ajanga, A., Crudder, C., Otido, J., Jukes, M.C., Clarke, S.E., Brooker, S. 2008. Relationships between anaemia and parasitic infections in Kenyan school-children: a Bayesian hierarchical modelling approach. International Journal for Parasitology, 38(14):1663-1671. [https://doi.org/10.1016/j.ijpara.2008.05.013]; Holding \& Snow, 2001; Lalloo, D.G., Olukoya, P. \& Olliaro, P. 2006. Malaria in adolescence: burden of disease, consequences and opportunities for intervention. The Lancet Infectious Diseases, 6(12):780-793. [https://doi.org/10.1016/S1473-3099(06)70655-7]; Brooker et al., 2008; Bundy, D.A.P., Lwin, S., Osika, J.S., McLaughlin, J. 7 Pannenborg, C.O. 2000. What should schools do about malaria? Parasitology Today, 16(5):181-2. [https:// doi.org/10.1016/s0169-4758(00)01658-6]; Bundy, D.A.P., Lwin, S., Osika, J.S., McLaughlin, J. 7 Pannenborg, C.O. 2000. What should schools do about malaria? Parasitology Today, 16(5):181-2. [https://doi.org/10.1016/s0169-4758(00)01658-6]. 
The efforts of major agencies have made rapid diagnostic testing and artemisinin combination therapy more affordable and hence more accessible; the benefits of now making teacher-driven diagnosis and treatment broadly available in endemic areas would be considerable. Arguably there is still no consensus as to the optimal intervention approach, and more evidence on the costs and cost-effectiveness for school-based malaria control is needed, but individual region-specific programmes can be tailored from the evidence now available to provide viable interventions for at-risk populations.

Many malaria-endemic countries are considering scaling up rapid diagnostic testing use in a variety of locations; it is not overstated to say, "that when well used, rapid diagnostic testing can transform fever management, reform understanding of malaria transmission, and have even made malaria elimination look achievable." ${ }^{162}$ There is a need for intersectoral collaboration at a national level, and only when this is realised is it likely that the effective upscaling of rapid diagnostic testing/artemisinin combination therapy availability will be achieved; legislative changes and investment in support programmes and infrastructure will be required in parallel. ${ }^{163}$ However, it is significant that effective rapid diagnostic testing rollout on a national scale has already been achieved in Senegal through well-planned policies and structured implementation. ${ }^{164}$

In addition to being simple to implement and low cost, the rapid diagnostic testing/artemisinin combination therapy model uses WHO-endorsed testing and treatment methods, so has broad relevance and is applicable to low-resource settings worldwide where the school-age population is at risk. Such models already meet calls from the WHO Commission on Social Determinants of Health to adopt a community empowerment approach, use 'non-traditional outlets' and 'improved tools' to address health challenges faced by young people, and seek longer and healthier lives for Africans. Future models that use novel ways to engage and train teachers to deliver health education and elements of care will also meet recommendations from the Lancet Commission on the future of health in subSaharan Africa to extend population access to services, by using 'people-centred approaches' and innovative education and training of personnel that correspond to local needs. ${ }^{165}$

162 Thiam et al., 2011.

163 Afenyadu et al., 2005; Akweongo et al., 2011; Visser et al., 2017.

164 Thiam et al., 2011.

165 WHO, 2008; Sachs \& Malaney, 2002; Agyepong et al., 2017. 


\section{Conclusion}

Initiatives are needed to address the current epidemic of non-communicable diseases, but to be effective, when school-based health education programmes on $\mathrm{DOHaD}$ are implemented, they must be delivered to children who are healthy enough to be able to attend school and well enough to learn. Hence the importance of providing measures that address the negative impact of malaria, and other remediable social determinants of health that negatively impact a child's ability to benefit from education, in parallel with $\mathrm{DOHaD}$-related school programs.

Growing awareness of the negative impact of malaria on school-age children has stimulated the search for interventions that can be delivered through schools to address mortality and morbidity. However, what agent(s) and mode of delivery constitute the optimal regimen in a given population, or endemic area is as yet undefined. A broad selection of literature now describes the rationale, therapeutic options, design, delivery, training, effectiveness, cost, challenges and future research priorities for interventions applicable to school-based delivery. The argument for universal, parasite-based diagnosis is clear; rapid diagnostic testing can provide poorly resourced, malaria-endemic populations with access to diagnosis, with a comparable level of accuracy to hospital-based diagnostics; and artemisinin combination therapies are effective and affordable therapy. Innovative ways are called for to make these WHO-endorsed entities more available to those in need, and globally schools offer more than one billion children the potential to benefit from school-based healthcare delivery.

Teachers can be effective agents for change. Innovative school-based models that engage and train teachers to deliver health education and elements of care are advocated by the WHO as a means to address all aspects of disease, and creative school-based interventions are sanctioned as a way to tackle health challenges faced by young people. Such models also meet recommendations from the Lancet Commission on the future of health in sub-Saharan Africa to extend population access to services by using 'people-centred approaches' and innovative education and training of personnel that correspond to local needs.

However, community interventions to educate and promote health in the context of the developmental origins of health and disease must also encompass diagnosis and treatment strategies for malaria where the disease is endemic, as the reduction in morbidly obtained will translate into improved school attendance and a higher capacity to learn, which will greatly increase the probability of any $\mathrm{DOHaD}$-related education strategy being effective. 


\section{Acknowledgements}

The author thanks the Stellenbosch Institute for Advanced Study for the invitation to work at the Wallenberg Research Centre in Stellenbosch as a Fellow in Residence. The school-based teacher-driven rapid diagnosis and treatment project in Uganda central to this chapter was funded by the Hillman Medical Education Fund, Canada, and our teams gratefully acknowledge the dedication of the teachers, parents and children who participated. Literature searches included in this chapter were part of related research publications on malaria, and invited presentations at the International Pediatric Association, Canadian Pediatric Society, International Conference(s) on Applied Science and Health, and the STIAS seminar series. 